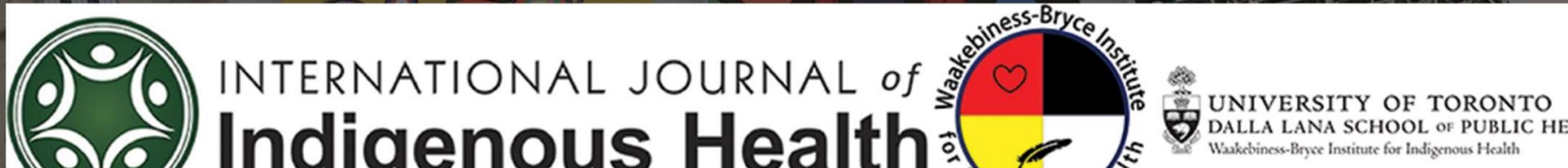
Indigenous Health
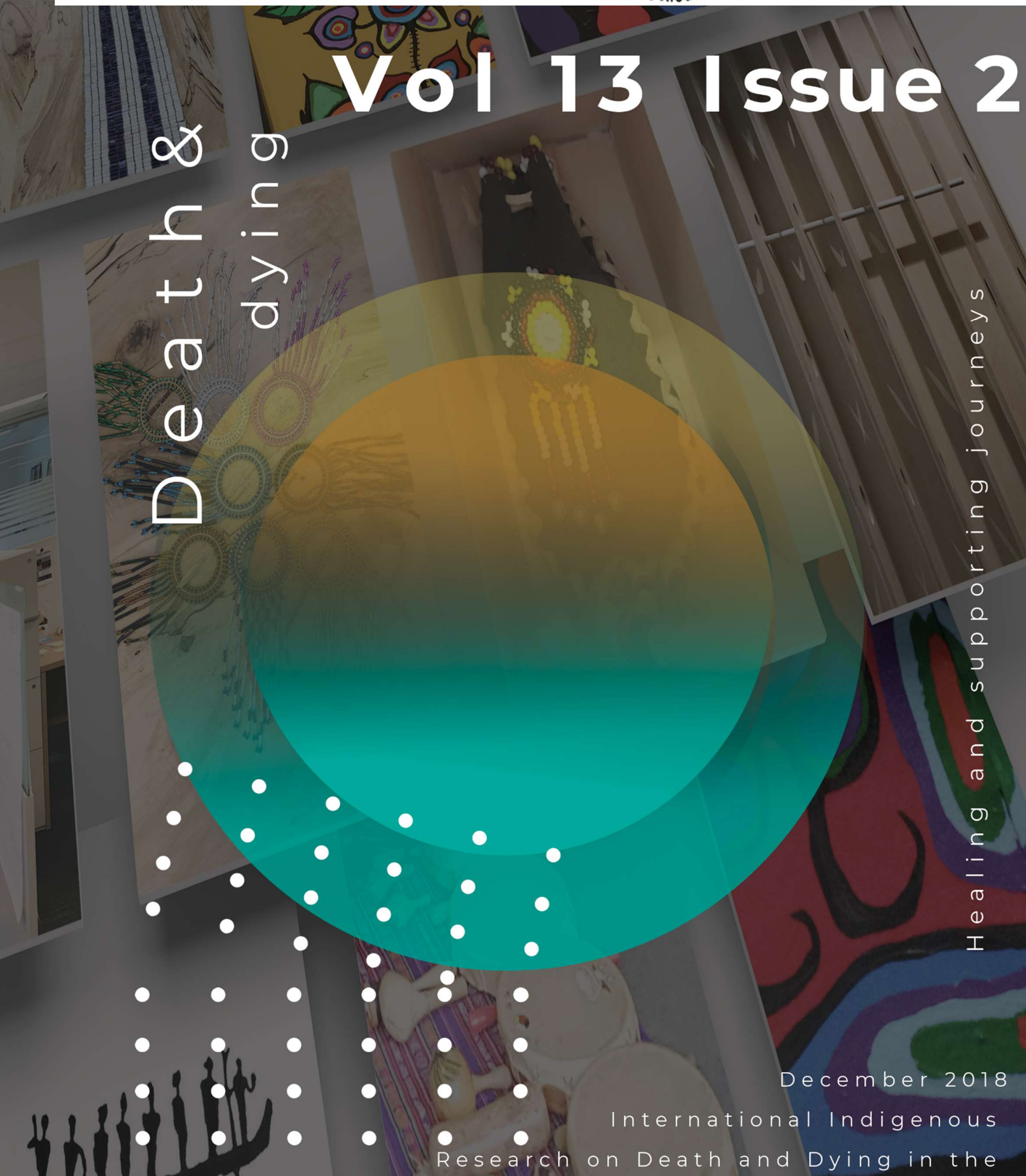

enous

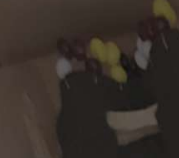




\section{Cover Page Artwork:}

Images of healing medicines and ancestral Indigenous knowledge set the background where holistic view of live is represented by the circle and the sunrise and sunset continuum, an art navigation and transition between colors and worlds.

Author: Juan Carlos Rodriguez, 2018.

Waakebiness-Bryce Institute for Indigenous Health 


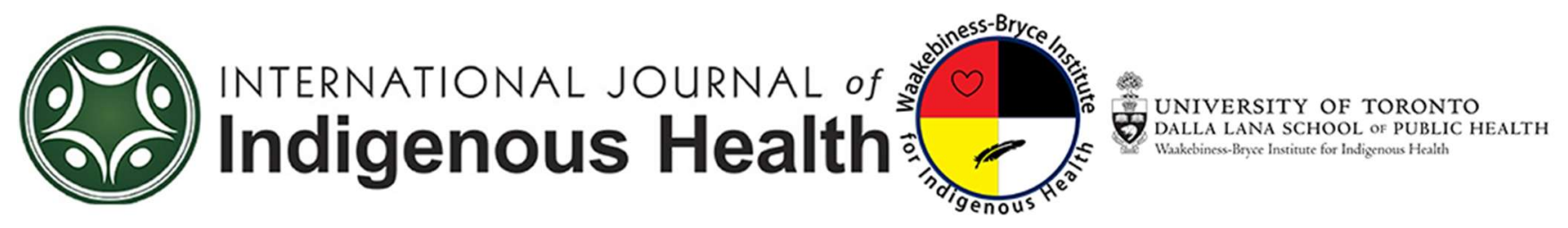

Editorial

$3-7$

Articles

8- 28

$30-46$

$48-60$

Editorial

Suzanne Stewart, Angela Mashford-Pringle.

Waakebiness-Bryce Institute for Indigenous Health, Dalla Lana School of Public Health, University of Toronto.

Rethinking Indigenous Suicide.

Jeffrey Ansloos

Toku toa, he toa rangatira: A qualitative investigation of New Zealand Māori end-of-life care customs.

Tess Moeke-Maxwell, Rawiri Wharemate, Stella Black, Kathleen Mason ,Janine Wiles, Merryn Gott.

The End of Life is an Auspicious Opportunity for Healing: Decolonizing Death and Dying for Urban Indigenous People.

Michael Anderson 


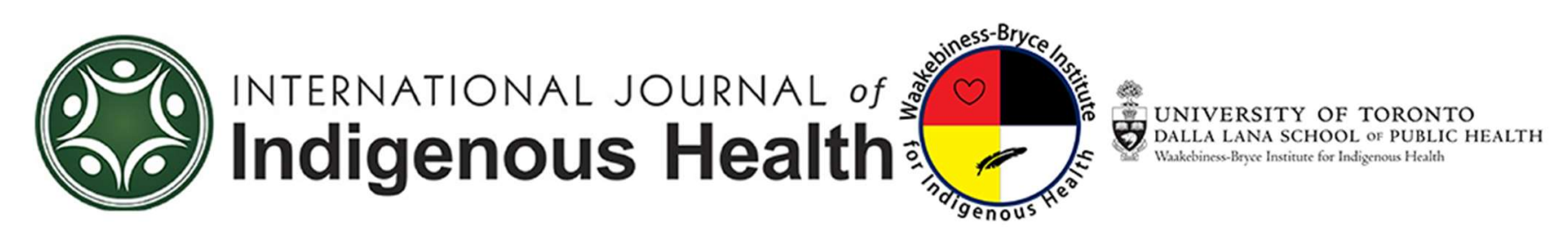

\section{Publisher}

Waakebiness-Bryce Institute for Indigenous Health

Research, Dalla Lana School of Public Health, University of Toronto

\section{Editor}

Suzanne Stewart, Angela Mashford-Pringle

\section{Editorial Advisory Board}

Heather Castleden, Suzanne Christopher, Margo

Greenwood, Maura C. Hanrahan. Rod McCormick, Julianne Sanguins

\section{Copy Editor}

Mikaela Gabriel

\section{Manager Editor}

Juan Carlos Rodriguez

\section{Assistant}

Michael Auksi

\section{Cover Design and Layout}

Juan Carlos Rodriguez.

\section{Editorial Office}

International Journal of Indigenous Health,

Waakebiness-Bryce Institute for Indigenous Health, Dalla Lana School of Public Health,

University of Toronto, 155 College Street, Suite 40, Toronto, Ontario M5T 3M7

http://jps.library.utoronto.ca/index.php/ijih/index

ISSN 2291-9368 (Print) 2291-9376 (Online)

Volume 13, N2, DOI:10.18357/ijih.v13i2.32023

\section{December 2018, Volume 13, Issue 2}

The International Journal of Indigenous Health is a peer-reviewed publication of the WaakebinessBryce Institute for Indigenous Health at the Dalla Lana School of Public Health, University of Toronto.

\section{Copyright/Permission to Reproduce: The}

International Journal of Indigenous Health has an exclusive license for the articles published herein, limited to first right of publication granted by the author(s) who hold copyright. The WaakebinessBryce Institute for Indigenous Health provides free, open access to the articles herein. Articles herein are covered by applicable copyright law and Creative Commons license granted to the International Journal of Indigenous Health by the author(s) that allows readers fully credited use and reproduction and prohibits any derivative or commercial use of the article(s) published in the International Journal of Indigenous Health.

\section{Disclaimer}

The International Journal of Indigenous Health is funded by the Waakebiness-Bryce Institute for Indigenous Health (WBIIH). The views expressed herein do not necessarily represent the view of the WBIIH, the Dalla Lana School of Public Health, or the University of Toronto. The articles represent the views of the authors and do not necessarily reflect the views of WBIIH. WBIIH at the University of Toronto assumes no responsibility or liability for damages arising from any error or omission, or from the use of any information or advice, contained in this publication.

\section{Subscription}

The International Journal of Indigenous Health is distributed free of charge through its website, which is online and open-access. If you wish to receive an email with the Table of Contents of newly released publications, please sign-up at http://journals.uvic.ca/index.php/ijih/user/register.

\section{Submissions}

The International Journal of Indigenous Health accepts article submissions on the topic of Indigenous health globally. All submissions should be submitted via online on the Journal website: https://ips.library.utoronto.ca/index.php/ijih/about ssubmissions 


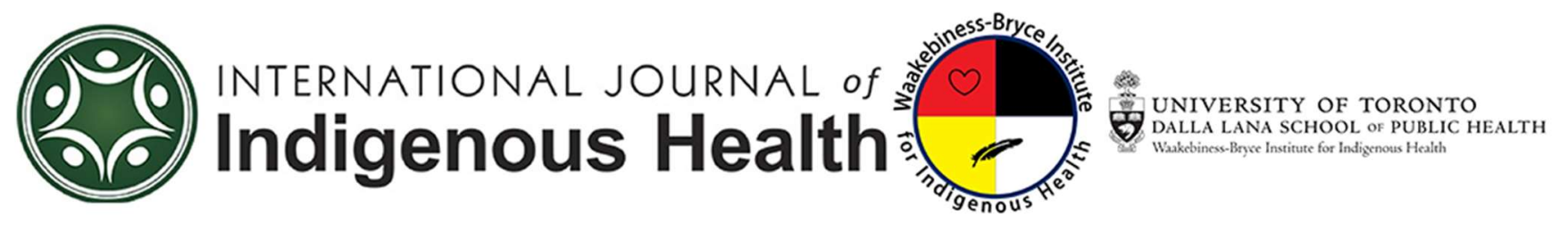

Volume 13

Issue 2. Death and Dying

Editorial

DOI 10.18357/ijih.v13i2.32019

December 2018

\section{Editorial}

In parts of the world, death and dying are considered taboo subjects; mainstream media covers death and dying as sensational dramatic event(s), or as entertainment, but rarely as a part of life and the life cycle. Many businesses and health care services rely on people attempting to avoid death by slowing the aging process (such as anti-wrinkle creams, hair dyes, cosmetic surgeries, etc.), which seems to lead people into a comfortable avoidance of the reality that dying is an imminent and intrinsic part of living. The capitalist economy is often based on preventing, slowing, or hiding death and dying in a manner that allows people to forget that death is a part of the natural order of life: birth, growing, aging, dying, and death happen to all creatures on earth. Avoidance of speaking, learning, teaching, or exploring death and dying have become the norm in most areas of society, including within health care settings, which can lead to fear, anxiety, depression, and an inability to live in the present moment. In seeking to avoid even the thought of death and dying, people may hope that it will not visit their family, community, or their own door, and believe that they have a long life ahead of them. Many Western cultures and countries commonly have relatively short funerals, with proceedings lasting less than a day, that are attended by family and friends of the deceased; often, these ceremonies and proceedings may invoke feelings of guilt, sadness, anxiety, and, often, the fear that death will visit others closely associated to the mourner. Yet, in other cultures such as Indigenous cultures worldwide, ceremony for death can last for days or weeks, with entirely contrasting perceptions surrounding mourning and loss.

The manner and methods of dying are often disparately addressed, both socially and emotionally, in society. Those who die from chronic or prolonged diseases are addressed much differently than those who die sudden deaths. When a loved one is in palliative care, there is more mental and emotional preparation among family, friends, and community members for the passing of their relation. This grieving process is unique to each individual, and no one truly knows how they will cope with such loss until they experience the death of someone close to them. However, there is no manner of preparation for those who lose a loved one suddenly. When a person dies suddenly, whether through accident, unknown or acute illness/disease, homicide, or suicide, those close to the person are often at a great loss in coping with the impact of the death; there was no time for preparation, no advanced notice of oncoming grief, no chance to say goodbye. Sudden death can have tremendous and multiple impacting effects on family and friends that need an opportunity to make sense of the death in order to begin to 
grieve. Western medicine term sudden death by another name: premature death. However, outside of medical predictions, people do not know when their so-called 'expiry date' will be upon them.

For many Indigenous communities around the world, death and dying are part of spiritual teachings, and are deeply embedded in traditional cultural knowledges. There are different cultural teachings about death and dying in the diversities of Indigenous cultures on Turtle Island and across the world; however, these are seldom written or articulated beyond members of communities. Indigenous individuals often experience difficulty in discussing spiritual and pragmatic matters of dying with biomedical health professionals, as they are often non-Indigenous, and hold Western values and beliefs about death and dying. For example, in Anishinaabe teachings on life and death, a person's spirit enters the world through the birth of a child in the eastern door, and exits the world through the western or northern door when the work of the spirit is finished on Mother Earth. Other Indigenous peoples have different teachings that surround the process of dying and death; these can be about the ceremonies, the protocols to be followed when a person is dying, end of life practices that should be adhered to, and support for the grieving process for the family and friends, as well as for the person facing death.

Avoiding discussion about dying and death will not prevent it or keep it at bay, but it will bring increased fear and anxiety towards death. This issue of the International Journal of Indigenous Health (Vol. 13(1)) received few submissions, but the Editors believe that Indigenous dying and death should be discussed. There is more than this issue can publish that can address the process of death, the ripple effects it has on others, and how Indigenous teachings can help Indigenous and non-Indigenous people alike through the grief, sadness, and loss experienced after a death. Death is a profoundly personal issue, and one that many people grapple with over the course of their lives. It is through personal experiences, deeper understanding, acceptance of individual mortality, and interpersonal support through grieving that allows people to find the strength and knowledge to understand and accept dying and death as part of life. The articles within this issue are but a starting point for discussions on death and dying.

Included as part of this editorial is a personal narrative from one of our Editorial Managers, Michael Auksi, about his experiences with death and dying:

"My name is Michael Mahkwa Auksi. I grew up in Toronto and I am Ojibway-Estonian. In the winter of 2002, I traveled 24 hours by train to Sioux Lookout, Ontario. My goal was to represent the Lac Seul Eagles hockey team in the Northern Bands First Nations Hockey Tournament. This trip represented a turning point in my life. I got out of the big city, spent lots of time with my dad, and I began to feel good about myself again. While at the tournament, I recall hearing about a young person who had taken his own life in one of the communities. All the teams from this community removed themselves from the tournament and returned home to honour the memory of this youth. Back then, I would have had a hard time not staying at the tournament, but looking back on things, I think returning home was, without a doubt, the right thing to do.

The loss of loved ones, from an Indigenous perspective, is community-oriented. When I worked at one of Toronto's Indigenous agencies, there were, sadly, a number of instances of young people who had passed away. Each time someone passed away, many of the 
community's youth paid their respects by volunteering to fire-keep at the sacred fire that was lit as part of the ceremony and protocols of death. I recall hearing stories from community members about the tireless efforts of youth, some of whom stayed at the sacred fire for three days straight.

The subject of death and dying for myself has always been relatively confusing and disorienting. All four of my grandparents made their journeys to the spirit world when I was very young. I do remember visiting with three of my grandparents and feeling their warmth and love, which is why I'm extremely attentive when my parents speak to me about their parents.

Other experiences I have had with death and dying comes from the loss of two of my friends from high school: one friend passed away from Hodgkin's lymphoma, and my other friend passed away in a tragic accident. These losses act as a reminder that I must pay attention to those I love, as often and as much as possible. I do my best to visit and phone my parents regularly and use every opportunity to tell them that I love them, and thank them for all their support and love.

How do Indigenous Peoples cope with the loss of their loved ones? From my experience, there exists both contemporary and traditional end-of-life ceremonies. I've attended primarily contemporary ceremonies. I remember being at my Aunt Lorraine's traditional funeral in Lac Seul First Nation. At the time, I think it was the first time I'd seen my father cry. Dad and I have cried together a few times since then, and I feel that it's been a great way to release our emotions in a healthy way. I remember the healing power of seeing my aunty resting peacefully on a beautiful blanket surrounded by the sacred medicines, strawberries, and various other important items. The whole community seemed to be there as we honoured and celebrated my Aunt Lorraine.

The next logical question is: how do Indigenous individuals perceive their own mortality? It's certainly not for me to assume anything, but now in my mid-30s, I have found myself considering my own mortality more than before. It is something we all have to face in our lives, and it is certainly never easy. We all reflect on our own mortality at some point in our time here in the physical world; I can stir up feelings of fear, possibly because death represents one of life's most thought-provoking unknowns. However, as the following story illustrates, comfort can sometimes be found when discussing the subject of death and dying:

It was a day like any other and my dad was at the auto shop in Dryden, Ontario having his truck, "Old Blue", worked on. While in the office, Dad struck up a conversation with another Ojibway man. Before long, they were chatting as if they'd known each other for years. The man shared a story from many years ago with my dad. The man had been asked by a nurse at the hospital in Kenora if he could translate for a man who was preparing to make his final journey. The man in the hospital spoke in Ojibway, "I can see the spirits. They have come for me." The Ojibway-speaking man in the story was my grandfather. A 
powerful life force had brought this person and my dad together. Dad was given the gift of one more visit with his dada. This story has brought a great sense of comfort to both my dad and myself as we carry on the legacy of John Kenny, legendary hunter, trapper, fisherman and provider.”

We want to thank you for your continued support of the International Journal of Indigenous Health.

Miigwetch/Thank you,

Dr. Suzanne Stewart \& Dr. Angela Mashford-Pringle, Co-Editors

Follow the International Journal of Indigenous Health at: https://jps.library.utoronto.ca/index.php/ijih/index

\section{Creative Commons Licence} (ब) $\odot \Theta$

This work is licensed under a Creative Commons Attribution-Noncommercial-No

Derivative Works 4.0 License.

Recommended Citation:

Stewart, S., Mashford-Pringle, A. (2018). Editorial. IJIH, 13(2), 3 - 7.

https://doi.org/10.32799/ijih.v13i2.32019 


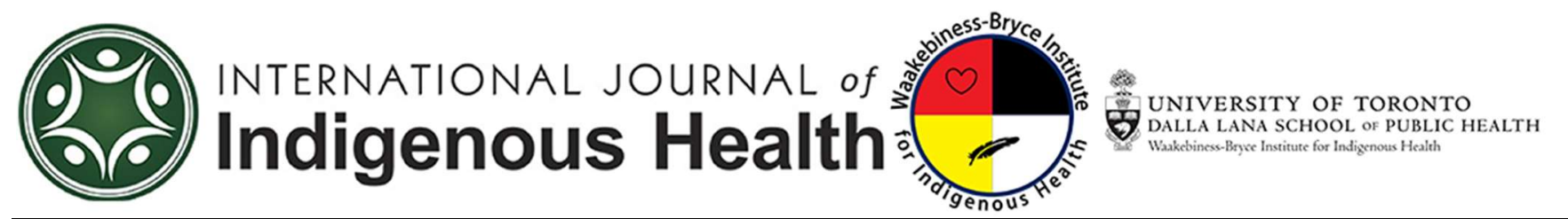

Volume 13

Issue 2. Death and Dying

Article 1

DOI 10.18357/ijih.v13i2.32061

December 2018

\section{Rethinking Indigenous Suicide}

\section{Jeffrey Ansloos, PhD}

Assistant Professor, Department of Applied Psychology and Human Development, OISE, University of Toronto.

Email: jeffrey.ansloos@utoronto.ca

Follow the International Journal of Indigenous Health at:

https://jps.library.utoronto.ca/index.php/ijih/index

\section{Recommended Citation}

Ansloos, J. (2018). Rethinking Indigenous Suicide. IJIH, 13(2),8-28. DOI 10.18357/ijih.v13i2.32061 


\title{
Rethinking Indigenous Suicide
}

\begin{abstract}
Suicide is one of the most significant issues facing Indigenous communities throughout Canada. The rate of Indigenous deaths by suicide is severely disproportionate to that of the general public. While the last three decades have seen substantial investments in suicidology research within the Canadian context, rates of Indigenous deaths by suicide have remained relatively stable, and little remains known about effective means to reduce Indigenous deaths by suicide. A movement of critical suicidology scholars across health and social sciences is beginning to challenge the mainstream approach of suicidology research and suicide prevention, citing concerns about the ideological and epistemic foundations. In this article, the author highlights how these critiques are relevant to Indigenous contexts. Challenging a range of assumptions, the author considers the need to rethink the ideological foundations of research on Indigenous suicide. Finally, the author considers two methodological projects that are integral to forming a critical approach to Indigenous suicidology research and Indigenous suicide prevention praxis-culturally grounded research and decolonizing research.
\end{abstract}

\section{Keywords}

Indigenous suicide, Indigenous suicide prevention; Indigenous mental health; Critical suicidology; Indigenous youth suicide; Decolonizing methodologies; Suicidology; First Nations; Aboriginal; Indigenous health; Social determinants of health.

\section{Creative Commons Licence}

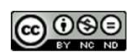

This work is licensed under a Creative Commons Attribution-Noncommercial-No Derivative Works 4.0 License. 


\section{Introduction}

Taking up the theme of Indigenous death by suicide, this article was first presented as a keynote at the 2018 Indigenous Mental Health: Death and Dying Symposium at the University of TorontoWaakebiness Bryce Institute for Indigenous Health.

I, the author, am nêhiyaw (Fisher River Cree Nation) and have worked in the field of Indigenous mental health for the last decade, as an educator and a psychologist. This article takes as its starting point the challenge that mainstream approaches to suicidology and suicide prevention have proven woefully inadequate to address the challenge of Indigenous suicide and require a critical reformulation. The purpose of this article is to draw attention to the issue of Indigenous suicide and the enduring social and structural dynamics influencing high prevalence rates within Indigenous communities. In conversation with the emerging movement of critical suicidology, I want to challenge the assumptions of mainstream approaches to suicide prevention with Indigenous peoples, raising critical concern for how these approaches fail to address the key social and structural dimensions of Indigenous suicides.

While Indigenous health and social policy frameworks in Canada have acknowledged the importance of social and structural dimensions of Indigenous suicide, the predominant approaches to research have rarely examined these dimensions, nor have the approaches to prevention (White \& Mushquash, 2016). There is an urgent need for these factors to be more seriously considered within health and social research on suicide. Finally, I want consider what critical approaches to Indigenous suicide studies ought to attend to methodologically, specifically in terms of sociocultural and structural dimensions of suicide, as well as how Indigenous suicide prevention praxis might be reimagined in light of these dimensions.

\section{Method}

The following article utilizes a targeted literature review method, also sometimes referred to as a focused literature review (Huelin, Iheanacho, Payne \& Sandman, 2015). As a non-systematic review of literature, the goal of this approach is to provide relevant and informative information related to a topic, as opposed to an exhaustive account. Literature selection is iterative and does not follow a predefined protocol. Selection is based on relevance in order to explicate ideological trends and build understanding of the current critical tensions in the field. As this article was initially presented in the context of a symposium, this methodological approach was selected to develop a foundational understanding of some

of the contextual and historical bases of the status of Indigenous suicide research in Canada, as well as to provide an introduction to the emerging movement of critical suicidology. The results of this review highlight important contextual information about Indigenous suicide studies, the emerging 
methodological contributions of critical suicidologists, and considerations of the implications of integrating critical and Indigenous approaches in suicide prevention research.

\section{Context}

In this first section, I provide a brief overview of the prevalence of suicide among Indigenous Peoples in Canada at the population level, with attention to the historical and contextual factors associated with prevalence and some limitations of the current knowledge base.

\section{Prevalence of Suicide among Indigenous People in Canada}

According to the 2016 federal census, roughly 1.7 million people in Canada self-identify as Aboriginal, including First Nations, Métis, and Inuit (respectfully named Indigenous hereon in), and constitute the fastest growing population (Statistics Canada, 2016). Nonetheless, Indigenous Peoples in Canada continue to experience substantial social and health inequities. Currently, it is estimated that suicide rates are 5 to 7 times higher for Indigenous youth compared to non-Indigenous youth in Canada, and for Inuit youth 11 times higher than the national rate for non-Indigenous youth (Government of Canada, 2018).

In the early 1990s, the Royal Commission on Aboriginal Peoples released a report (1995) concerning the disproportionately high rates of Indigenous deaths by suicide and suicide ideation among Indigenous people. Based on national health data from 1987-1991, the commission report estimated that the suicide rate for Indigenous people in Canada was 2-3 times higher than non-Indigenous peoples. When accounting for variables such as age, the suicide rate of Indigenous youth was 5-6 times higher than non-Indigenous youth. There was also significant regional diversity in suicide at this time with Inuit youth in Northern Quebec being 20 times more likely than non-Indigenous youth to die by suicide (Kirmayer, 1994); and First Nations youth in British Columbia dying by suicide 4.5 times the rate of non-Indigenous youth (Chandler \& Lalonde, 1998).

Since the early 1990s, the rates of Indigenous youth suicide have remained relatively unchanged, and in some cases, have increased (Government of Canada, 2017). Presently, the leading cause of death for Indigenous people under the age of 44 is suicide (Kuman \& Nahwegabow, 2016). While there is documented variation in suicide rates between First Nations and Inuit youth, and there is currently no population health information on the status of Métis youth suicide rates.

Based on geozoning data collected by Statistics Canada, Health Canada (2013) reported that the suicide rate among on-reserve First Nation male youth (ages 1-19) was 30 per 100,000, and the rate for on-reserve female youth (ages 1-19) was 26 per 100,000 between the years of 2005-2007. Based on the 
Statistics Canada, Aboriginal Peoples Survey in 2012 approximately 17\% of First Nations young adults (ages 18-25) and 25\% First Nations adults (ages 26-59) living off-reserve reported suicidal ideation within their lifetime (Kuman \& Nahwegabow, 2016).

Similarly, the Inuit Tapiriit Kanatami (ITK; 2016) suggests that across the four Inuit regions (Nunangat), suicide rates vary from 5-25 times the national suicide rate (60 per 100,000 in Inuvialuit; 275 per 100,000 in Nunatsiavut; 113 per 100,000 in Nunavik; 116 per 100,000 in Nunavut). When accounting for variables such as gender and age, Inuit males are the most at-risk group for suicide, with male youth (ages 15-29) completing suicides at a rate 40 times the national average. According to Statistics Canada (2012), between 2004-2008, children and youth in Inuit Nunangat were 30 times more likely to die by suicide than non-Indigenous youth. Among Métis peoples, 16-20\% of adults (ages 1859) reported suicidal ideation within their lifetime (Statistics Canada, 2012).

It is important to point out that there is a serious limitation in what can be reported in terms of actual rates from a national standpoint. Currently, there are no national governmental systems to track records of Indigenous suicides across the country. Provinces and territories have varying practices in this regard. The majority of provinces and territories currently report suicides to a vital events database, however there are no mechanisms to identify which of these deaths are of Indigenous peoples, nor are there currently any Indigenous suicide surveillance public health systems. Indigenous governmental organizations and advocacy groups (i.e., Assembly of First Nations, the Inuit Tapiriit Kanatami, and Métis National Council) have no formal mechanisms to monitor incidences of suicide, however, some community-specific tracking has occurred (i.e., Nishnawbe Aski Nation).

According to the Indigenous and Northern Affairs Standing committee report, the data on Indigenous suicide rates that are currently available are likely under-representative due to inconsistent reporting mechanisms, as some deaths by suicide are reported as accidents, and ethnicity is not reported on death certificates (Government of Canada, 2017). Nonetheless, some Indigenous nations and Indigenous community organizations have been monitoring data on suicides within communities. For example, Nishnawbe Aski Nation (the Grand Council for Treaty No. 9) has documented over 562 deaths by suicide since 1986 across their 49 member communities (Troian, March 2018). Consistent with national estimates, $50-60 \%$ of these deaths were men and $40 \%$ were youth. The Truth and Reconciliation (TRC) Commission of Canada's Calls to Action (2015) specifically address the need for national data on suicide and called for governments to develop mechanisms and indicators to address Indigenous health disparities, including suicide. To date, both calls to action on suicide have not been acted on (CBC, 2018; See Table 1). 
Table 1.

TRC Call to Actions on Suicide

Call to Action

Description

Status

19: Identify and

close the gaps in

health outcomes

between

Aboriginal and non-Aboriginal communities

55: Provide annual reports or any current data requested by the National

Council for

Reconciliation
"To establish measurable goals to identify and close the gaps in health outcomes between Aboriginal and non-Aboriginal communities, and to publish annual progress reports and assess long term trends. Such efforts would focus on indicators such as: infant mortality, maternal health, suicide, mental health, addictions, life expectancy, birth rates, infant and child health issues, chronic diseases, illness and injury incidence, and the availability of appropriate health services" (TRC, 2015, 2-3)

Incomplete

"We call upon all levels of government to provide annual reports or any current data requested by the National Council for Reconciliation so that it can report on the progress towards reconciliation. The reports or data would include, but not be limited to ... Progress on closing the gaps between Aboriginal and non-

Incomplete

Aboriginal communities in a number of health indicators such as: infant mortality, maternal health, suicide, mental health, addictions, life expectancy, birth rates, infant and child health issues, chronic diseases, illness and injury incidence, and the availability of appropriate health services." (TRC, 2015, 6).

\section{Critical Movement in Suicidology and Suicide Prevention}

The research in suicidology and suicide prevention is diverse, encompassing a variety of conceptual frameworks. While suicide is a dynamic and multidimensional phenomenon that has historically been studied from a wide range of perspectives (Hjelmeland, 2012), over the last 30 years, the biological view of suicide has dominated. This has meaningfully coincided with the professionalization of mental health services within health and social services settings, causing a biopsychological view to monopolize the field of suicidology research (Hjelmeland \& Knizek, 2016, 2017; Marsh, 2010).

White (2017) has argued that "within mainstream suicidology, suicide has come to be understood as a static, individual, and recognizable phenomenon" and that this "received view" of suicidology and suicide prevention assumes an individualistic, psychiatric, and positivist epistemic hegemony. Marsh (2010) has offered similar criticism, calling this hegemony "a compulsory ontology of pathology" (p. 28). He argues that the mainstream is guided by a "regime of truth"-assumptions of the meaning of 
suicide (i.e., that suicide is an individualistic psycho-pathology) and the study of suicidology (i.e., that suicidology is a science).

Over the last decade, in response to this mainstream approach, a critical movement in suicidology has been forming. The Critical Suicidology Studies Network (2018) describes this movement in the following way:

Many within suicide research have become frustrated by the limitations of dominant pathologizing and medicalized approaches to suicide research and prevention practices. Believing that suicidology is in need of a critical re-thinking of its subject matter and a broadening of it disciplinary basis, they look at cultural practices of making sense of suicide, taking into account how suicide is shaped by history, politics, gender, identity, culture, media and power ... A suicidology that operates with a singular form of evidence or truth loses the possibility of creativity and plurality in developing new approaches to help address and understand suicide. ()

Methodologically, critical suicidology is concerned with "critically oriented agendas and theoretical frameworks, including feminist, constructionist, post-structural, postcolonial, antiracist, queer, critical, and activist perspectives" (White, 2017, p. 475). In conversation with critical suicidology, I want to consider this "received view" of suicidology and suicide prevention with an eye towards how the assumptions of this approach are shaping the field of Indigenous youth suicide prevention.

\section{Assumptions of Mainstream Suicidology}

Suicide as a pathology of the individual self. The predominant conceptualization that permeates much of mainstream suicidology is that the processes that lead to death by suicide originate inside of, or are at least internal to an individual-or a self (Jaworski, 2014). As White (2017) has suggested, "this essentialist, self-determining, intentional self is understood to be 'behind the act' of youth suicide" (p. 474). As such, the dominant methodologies to study the issue of suicide are atomistic, invested in the development of profiles of the suicidal person (e.g., risk factors). White (2017) notes that mainstream suicidology is "typically focused on identifying the psychopathologies, biological predisposition, personality traits, and cognitive characteristics that are assumed to exist within individuals and are understood to be the primary causal drivers leading to the outcome of suicide" (p. 474). By extension, the praxis of prevention is enacted upon individuals to prevent the lethal self. As an example, the World Health Organization (WHO, 2014) currently summarizes the profile of individual risk for suicide by including the following:

- Previous suicide attempt

- Mental disorders 
- Harmful use of alcohol

- Job or financial loss

- Hopelessness

- Chronic pain

- Family history of suicide

- Genetic and biological factors

With exception to contextual and situational factors identified (such as socio-economic instability), all of these individual factors reinforce the notion that the suicidal self is a disordered and/or pathological self. The suicidal person in this light is contrasted against a coherent and healthy self. As White (2017) suggests, "by carefully attending to the use of familiar binaries and taken for granted categories within suicidology, we are able to see how certain cultural values and assumptions permeate the construction of the suicidal self (and its implied solutions)" (p. 474). The values conveyed are consistent with the post-enlightenment thinking that permeates much of western psychology (Cushman, 1995; Ansloos, 2017). Regarding profiles of risk within the history of suicidology, the representation of the suicidal self is often male-centric and disordered (Jaworski, 2014). This is consistent with the current framing of the population level studies on Indigenous suicide in Canada. As noted in the introduction of this article, the Indigenous suicidal self is consistently represented as youthful and male. As such, substantial investments have gone into national efforts for youth suicide prevention research, at times often to the exclusion of critical Indigenous knowledge holders, traditional elders, and dynamic kinship networks, communities and families. As an example, the National Aboriginal Youth Suicide Prevention Strategy (NAYSPS, 2013) Program Framework summarizes the current state of research on the profile of Indigenous youth who are at-risk for death by suicide:

- Addictions (abuse/misuse)

- Previous attempts, a family history or community 'legacy' of suicide

- Social isolation, racism, rejection, bullying (cyber included)

- Problems in school

- Abuse (sexual, physical, child maltreatment and neglect)

- Lateral violence

- Mental illness (psycho-biological factors)

- Conflict with the law

- Poverty and unemployment

- Breakdown and/or loss of cultural values and belief systems

- Accumulation of trauma and intergenerational trauma (e.g. residential schools and child welfare systems)

- Extreme interpersonal conflict or the loss of a major relationship

- Dislocation from land

- Barriers to accessing health care, especially mental health and substance abuse treatment

- Rapid cultural change (colonization, erosion of traditional practices) 
In comparison to the WHO, this list is far more situational and social factors, and the research echoes much of the "mainstream view" of the suicidal self - one that is compromised by issues of substance use, epigenetic vulnerability, academic difficulties, psycho-biological pathologies, and a traumatized self. Such individualistic paradigms fail to "acknowledge the complexity of identity in a relational worldview ... Indigenous approaches extend relationality into complex and dynamic spheres that go beyond the confines of an enlightenment notion of identity or self-hood." (Ansloos, 2017, p. 11). Critically speaking, while social factors are present in the Indigenous list, they have not become the focus of research in part because the foundational conceptualization remains atomistic. What might occur if the relationality and socio-centric perspectives framed suicidology?

White (2017) notes that in such profiles "we also see the way that social contexts, structural arrangements, and historical relations of power are typically erased" (p. 474). Within the Canadian contexts, health sciences, and specifically the applied fields of mental health have been complicit in the actions of the Canadian state in the perpetration of colonial violence (Ansloos, 2017; CPA-IPPS, 2018) in ways that have further reinforced western ways of knowing and being that undermine Indigenous concepts of persons, and more broadly, Indigenous epistemologies and ontologies.

Suicide as psychological. Within the mainstream approach to suicidology, Marsh (2010) suggests "the position that suicide arises as a consequence of mental illness is often presented as an indisputable scientific and medical fact" (p. 27). For example, the Mental Health Commission of Canada (2018) asserts that "suicide and mental health are deeply connected -- it's estimated that $90 \%$ of people who die by suicide were experiencing a mental health problem or illness" (para. 1). The research base from which this claim is derived uses a methodology of psychological autopsy (Cavanagh, Carson, Sharpe, \& Lawrie, 2003) which has been critically contested (Marsh, 2010; Hjelmeland, Dieserud, Dyregrov, Knizek, \& Leenars, 2012). Nonetheless, this psychological notion dominates the field of research as well as the public perception.

White (2017) describes this approach as a "psycho-centric" conceptualization of suicidal distress (p. 474) and argues that such descriptions yield an approach to practice which is largely guided by individual psychological and psychiatric interventions. In operating from this assumption that suicidal people are mentally ill, critical suicidologists contend that critical alternatives are ignored or erased, especially those which implicate structural forms of violence. When the mainstream argues that suicide is fundamentally the product of impaired and/or disordered psychological wellbeing, the praxis of suicide prevention becomes concerned with the surveillance of suicidality (because it is framed to be indicative of psychopathology and the risk of death), and the treatment of psychopathology (because it is framed to be the solution to the problem).

In the 1995 special report on suicide from the Royal Commission on Aboriginal Peoples (RCAP), it is made clear that suicide was one of the most pressing issues facing Indigenous peoples and was disproportionately affecting youth. While the report acknowledged that there were biopsychological 
factors associated with suicide (i.e., mental disorders), the commission emphasized that other factors had greater bearing on Indigenous suicides, including (1) situational (e.g., disruptions of family life experienced as a result of enforced attendance at boarding schools, adoption, and fly-out hospitalizations), (2) socioeconomic (e.g., poverty, low levels of education, limited employment opportunities, inadequate housing, and deficiencies in sanitation and water quality), and (3) cultural stress (e.g., loss of land and control over living conditions, suppression of belief systems and spirituality, weakening of social and political institutions, and racial discrimination). Despite acknowledgement of contextual, cultural, social and structural factors, the primary approach to prevention continues to "generally involve findings ways to reduce risk factors and promote protective and preventive factors against suicide" (Government of Canada, 2018).

Marsh (2010) asks importantly, what are the "truth-effects" of the psychocentric position in suicidology, and further, "what forms of action follow on from such truths" (p. 29). In the Canadian context, the truth effects of a view that Indigenous suicides are a 'mental health crisis' is that the culture of intervention that has developed is singularly concerned with risk assessment, management, detection, and treatment of mental illness. The resulting form of action that follows is the promotion of mental health professions, which in turn result in destigmatizing the very psychotherapeutic practices that have long been critiqued by Indigenous scholars (Ansloos, 2017; Stewart, 2009).

This approach remains seemingly ineffective in reducing suicides, and therefore continues to be inaction on the socioeconomic and cultural distress dimensions articulated in the report by RCAP. Because of this preoccupation with the psychocentric view, White (2017) argues that "the received view of youth suicide is not well equipped to deal with these politics or paradoxes and thus represents an oversimplification of suicide's historical, ethical and sociopolitical complexity" ( $\mathrm{p} 476$ ).

Kral (1994) offers the idea that suicide is an idea or a logic, and that within the psychocentric lens, it is primarily a logic of a disordered mind. As such, suicide prevention becomes concerned with addressing disordered individuals. Within this narrow practice of mental health promotion there is a lack of engagement with logics informed by social and structural dimensions, which limits the range actions that can be engaged. What logics would emerge if we attended to the dynamic social and political logics of suicide in the Canadian state? A few studies have suggested that dimensions of economics (Lemstra et al., 2009), economic status (Wingert, 2011), cultural continuity (Chandler \& Proulx, 2006; Haggarty et al., 2008), climate change (Durkalec et al., 2015), gender (Lemstra et al., 2009), mobility (Berman et al., 2009; Snyder \& Wilson, 2015), contextual factors (Badry \& Felske, 2013), and education (OffetGartner, 2011) all influence the Indigenous wellbeing, but the persistent inaction in addressing these dimensions within suicidology research makes clear that "one of the consequences of a singular and individualistic reading of suicide is that it obscures colonial violence, racism, heteronormativity, patriarchy, social exclusion, capitalist green, and injustice and typically makes individuals responsible for making "it" better" (White, 2017, p. 474). 
Suicide as universal. In large part due to the psychocentric understanding of suicide, there has been an ethnocentric bias in the methodologies of suicidology and the practices of suicide prevention. While these frameworks signal an epistemological bias in contemporary suicidology (i.e., positivism), they are particularly problematic because they are unapologetically individualistic in conceptualizations and decontextualize suicide prevention practices from within the continuity of culture within communities (Colucci, 2006). Hjelmeland (2012) has argued that to prevent suicide, we need to understand what suicidal behavior means to people in their particular sociocultural context(s), and not to presume a onesize-fits-all approach (Rogers \& Soyka, 2004). In the context of Indigenous suicide prevention in Canada, this universalizing emphasis has resulted in profiling Indigenous peoples as a 'risky demographic' within a population analysis of health, with little understanding of the sociocultural context, or sociocultural meanings of suicides or traditions around suicide.

These decontextualized approaches to prevention are reductive, stereotyping, and ineffective. For example, simply having status as an Indigenous person is widely considered a 'social determinant' of suicide, however, there is great variation in suicide rates across Indigenous communities. In a study of youth suicide among First Nations communities in British Columbia, communities that had higher levels of "cultural continuity factors" such as self-governance, land claims, education, health care, cultural facilities, and police and fire service had lower rates of youth suicide compared to those with fewer of these factors (Chandler \& Lalonde, 1998).

Indigenous scholars have cautioned against a homogenous approach to research and intervention (Ansloos, 2017; Elliot-Groves, 2017). For example, there is substantial variation for Indigenous communities in suicide rates relative to the general population (Chandler \& Proulx, 2006) and for some communities, suicide is a relatively recent and rare occurrence (Leenaars, EchoHawk, Lester, \& Leenaars, 2007; Tatz, 2012). These challenges to the issue of universality necessitate research that attends to the intersectional meanings of identity (e.g., gender, sexuality), environment (e.g., rural/urban/northern; reserve/off reserve), social location (e.g., systems-involvement) and the heterogeneity of Indigenous culture and communities (e.g., with respect to governance) with regards to suicide.

While more broadly the field of mental health practices within Canada has been increasingly integrating culturally grounded approaches to healing within mental health services (Dell et al., 2011b; Maar \& Shawande, 2010; Puchala et al., 2010), much of this work fails to consider how Indigenous knowledge may be epistemologically dissonant with mental health paradigms (Ansloos, 2017).

Studying suicide with Indigenous peoples needs to be grounded in a "comprehensive approach that respects, values, and utilizes Indigenous cultural knowledge, approaches, languages, and ways of knowing" (First Nations Mental Wellness Circle, 2014. p. 1). That said, adopting a cultural lens on suicidology must occur through a framework that is broader than neoliberal multiculturalism. Nelson and Wilson (2017) point out that, "the remedies proposed by much of the research rely on a concept of 
'culture' which may reinforce multicultural ideals that, in turn, limit decolonization to the inclusion of 'cultural' activities within the colonial nation and preclude more substantial economic, jurisdictional and territorial decolonization" (p. 102). Ultimately, moving beyond a one-size-fits all approach must be anchored in a culturally focused approach, grounded in the social and material concerns of communities. Suicidology research must be ecological, contextually reflective, structurally-attuned and politically active.

Suicidology as a positivist science. Challenges to the issue of ethnocentrism and universality are ultimately entangled in broader debates on the methodological foundations of suicidology. Due to the biological emphasis, many treat mainstream suicidology as a science-often presuming an ethnocentric posture that is aligned with western positivism. This approach generates studies of suicide which are concerned with objectivity, standardization, measurement, and evaluation (White, 2017; Thomas, Bracken, \& Timimi, 2012).

In early suicidology scholarship, it was acknowledged that there were a variety of ways to conceptualize suicide as a social phenomenon including perspectives such as: theological, philosophical, demographic, sociological, psychodynamic, psychological, cognitive, biological, evolutionary, constitutional, biochemical, legal, prevention, global, political and supranational views (Shneidman, 1985). While a plurality of inquiry is possible, the majority of inquiry on suicide with Indigenous peoples has been dominated by positivist scientific inquiry. But critical suicidology asks us to consider, what types of research is now needed? As Hjelmeland (2012) has suggested, "it is high time to recognize the limitations of prediction, whether it is biological or otherwise, and instead focus on understanding suicide at the individual level in different sociocultural contexts" (p. 18).

There is increased interest from Indigenous communities across Canada to invest in new approaches to researching suicide and prevention. The National Inuit Suicide Prevention Strategy (2016), the Assembly of First Nations National Youth Council's Calls to Action for Life Promotion (2016), the First Nations Mental Wellness Continuum Framework (FNMWC, 2014), and the Truth and Reconciliation Calls to Action (2015) all call for approaches to research that are ecologically and contextually-informed and are relevant to the specific needs and aspirations of Indigenous communities. These frameworks all emphasize strengths-based and anti-oppressive approaches that are life promoting and that foreground Indigenous resiliency and sociopolitical alternatives to colonialism and racism (White \& Mushquash, 2016).

\section{Towards the Critical Study of Indigenous Suicide}

In reflecting on the central criticisms of the mainstream approach to suicidology and suicide prevention, it is clear that the main challenges raised are relevant to the dominant practices of research with Indigenous peoples. In this section, I engage with the question of what a critical Indigenous approach to suicidology might look like, and how future research and practices might be reimagined. 
Offered as two inter-related projects, I want to consider how our ideas about the meaning of suicide and approaches to suicide prevention change when we center the voices of Indigenous peoples, our values, methodologies, and social and political commitments.

\section{Centering Indigenous Culture}

In order to make critical changes to the dominant approach to suicidology with Indigenous peoples, a dynamic understanding of the vital importance of Indigenous culture is sorely needed, and this must be developed in a multifaceted way. In order for this to occur, suicidology researchers need a much more sophisticated theory of culture than has been provided by western social sciences. Our understanding of culture cannot be disembodied, abstracted, decontextualized, merely descriptive, or apolitical.

Aligned with the commitments of advocates for cultural approaches to suicidology and suicide prevention (Colucci, Lester, Hjelmeland \& Park, 2012), it is critical to understand how Indigenous knowledges and ways of being might shape our understanding of the phenomena of suicide. Wexler and Gone (2016) have suggested that "the underlying assumptions and tacit understands driving prevention initiatives are culturally incongruent for many Indigenous communities" and that we need "to take into consideration the culturally-mediated and socially negotiated ideas about the causes of and the appropriate responses to suicide" emerging from within Indigenous communities (p. 56). Further, ElliotGroves (2017) writes that in order "to address Indigenous suicide, it is necessary to design strategies that fit the unique social, cultural and human needs of each community" (p. 10). We must look to the ways that the embodied relationality of Indigenous culture (Ansloos, 2017) can give rise to life sustaining social practices and actions.

Further, the project of centering Indigenous culture must go further in that we must consider how the very practice of suicidology research could be re-envisioned by Indigenous research methodologies (Chilisa, 2012). The methodologies are diverse and contextual. The following questions are some of ways that the methodological innovations of Indigenous scholars could help us to ask different types of questions in suicide research:

- Given the emphasis on community-based epistemologies in Indigenous research (Kovach, 2010), what knowledge(s) about suicide and prevention are Indigenous people already generating beyond the hegemonies of academic scholarship, and how can we more deeply engage with Indigenous communities and the knowledge(s) they are stewarding and generating?

- In acknowledging the critical role of colonialism and distributions of power through colonial systems (Smith (2012) emphasizes the importance of critical analysis of power structures in Indigenous research and developing a multitude of decolonial projects. (Smith, 2012), How might questions about suicide evolve were we to have a robust analysis of historic and contemporary settler-colonialism? 
- Million (2013) emphasizes the central role of affect and lived experience as a means of producing Indigenous knowledge in relationship to violence. How can feeling and affect inform our understanding of the livability (or unitability) of life for Indigenous peoples, and how does feeling knowledge reconfigure what so-called 'truths' are known about suicide?

- What communal and environmental obligations would we be accountable for were we to study the issue of suicide in light of Indigenous relational ontologies-that is to say, social obligations to creator(s) and/or to kin, human and non-human (Hart, 2002)?

- How might the methods of researching suicide or prevention practices shift if research is as Wilson (2008) suggests ceremony, with protocols and ritual? Are there aspects of suicide that ought to remain unknowable?

- What if research is deeply personal and storied (Ansloos, 2018), and that the narratives we generate in suicidology hold power to make manifest new ways of being, or perhaps entire new worlds?

- How might the grounded-normativity of Indigenous culture (Simpson, 2017) re-determine who the audience of Indigenous suicide is? How might Indigenous youth's perspectives and preferences become centered in this field of research in a way that increases their own selfdeterminism?

There are many possibilities that open up for research in suicidology when we substantively engage the vast and evolving possibilities of Indigenous research methodologies. For every tradition and innovation of Indigenous knowledge, there is a way that research on suicide could become more methodologically contextual.

\section{Decolonizing in Suicidology and Suicide Prevention}

While decolonization is not the only critical methodological approach that may be needed in the context of Indigenous suicide research and prevention, in the context of ongoing colonialism, it must be a substantive commitment. Research and practices in the area of Indigenous suicide prevention are not occurring within a sociopolitical vacuum. They are occurring within the nationally endorsed era of reconciliation (TRC, 2015) as well as a time of unprecedented Indigenous movements of social action against ongoing forms of colonization. Further, with growing recognition that colonialism is a social dimension of suicide, decolonial inquiries in suicidology are not only valuable, they are ethically necessary.

Tuck and Yang (2012) have poignantly argued that "decolonization is not a metaphor" (p. 1) but rather is concerned with analyzing the material actions and effects of the colonial state's violence that is enacted upon Indigenous peoples-via dispossession or otherwise. In this sense, Indigenous analyses of colonialism could prove extremely useful in analyzing suicide. For example, the following questions are possible in conversation with decolonial scholars: 
- If the Indigenous body is a political order and/or an embodied expression of Indigenous sovereignty (Simpson, 2014), then what meanings beyond psychopathology does suicide enact on the body and within the settler-colonial context? What forms of action that are life affirming must be envisioned that might help Indigenous people actualize self-determinism in a world of constant colonial encroachment?

- How does an understanding of the environmental racism of colonialism, the treatment of homelands as wastelands (Lee, 2018), or the treatment of Indigenous life spaces as non-places, disposable or held in the grasps of enforced biosocial apartheid and misery (Belcourt, 2017) inform our understanding of questions of what makes a livable life?

- When the surveillance of all aspects of Indigenous life is the norm, and especially aspects which question the legitimacy of the settler state (Crosby \& Monaghan, 2018), how does suicide and the prevention of suicide become critically entangled in conversations of protest, agency, and embodied political self-determinism?

For Indigenous peoples, decolonization is not theoretical, it is an unsettling and active practice towards a radical resurgence of Indigeneity, expressing desire and enacting comprehensive selfdeterminism.

While the trendiness of citing 'social determinants' of suicide increases in the midst of continued psychocentric research, Indigenous articulations of critical suicidology must go further than simply citing the historic impacts of colonialism. Neoliberal acknowledgement of social determinants does not equate to actual or lived knowledge of colonialism, nor does it materially alter the material social conditions. Tuck and Yang (2012) point out that:

Fanon told us in 1963 that decolonizing the mind is the first step, not the only step toward overthrowing colonial regimes. Yet we wonder whether another settler move to innocence is to focus on decolonizing the mind, or the cultivation of critical consciousness, as if it were the sole activity of decolonization; to allow conscientization to stand in for the more uncomfortable task of relinquishing stolen land (p. 19).

Decolonial Indigenous research requires linking our political consciousness with accountable social actions. Decolonial projects in critical studies of Indigenous suicide and suicide prevention lead us to ask questions of how suicide research and the praxis of prevention can unsettle violence against Indigenous peoples and bring about justice.

Insofar as critical suicidologists need to articulate a theory of culture, we also need to articulate a theory of justice. White (2017) suggests that "one of the greatest possibilities that critical suicidology offers is the chance to change the conversation about youth suicide and prevention so that our practices can become more life activating, hopeful, justice seeking, community-building and creative" (p. 478). 
As such, decolonial projects in Indigenous articulations of critical suicidology are about a praxis of justice.

\section{Conclusion}

Along with scholars in critical suicidology (White, Marsh, Kral, \& Morris, 2016), and especially Indigenous scholarship (Elliot-Groves, 2017; Wexler \& Gone, 2016; White \& Mushquash, 2016), I am advocating for a substantive conceptual reorientation in suicide research with Indigenous peoples. It is clear that if we do not begin to make substantial changes to the status-quo of Indigenous suicide prevention research, the profound disparities will persist. This article has made clear that what we have known for more than 30 years, the prevalence of suicide for Indigenous people in Canada is high, disproportionate to the Canadian population at-large, and has remained stable and in some places worsened. The RCAP (1995) report made clear that the sites of prevention are within the social and structural dimensions of life for Indigenous peoples, such as addressing the profound effects of colonialism. This paper has highlighted a number of ways that the mainstream approach to suicidology fails to act upon these dynamics because it is oriented by hyper-individualistic, psycho-centric, ethnocentric, and positivist ideology. In order to move beyond this atomistic, reductive, stereotyping, and ineffective approach, we need to change course in suicide prevention research.

We need to do more than merely close the gap, we need to develop an approach to suicide prevention research which can nourish vitality, thriving, and wholeness of spirit in our communities. This article has suggested that in order to form a critical movement in Indigenous suicide research, we must be committed to centering a dynamic understanding of Indigenous culture. This will have comprehensive effects in terms of both the relevance of the practices of prevention that are formed, as well as the epistemological and methodological approaches to the practice of research itself. Further, this article has argued for an explicated commitment to decolonial polity within suicidology and Indigenous suicide prevention research. Indigenous communities face the ongoing effects of historical colonialism, and the contemporary effects of neocolonial violence. We need to begin to articulate an approach to research that can recognize the social and structural foundations of suicide in a way that goes beyond mere acknowledgement, towards material practices which promote holistic wellbeing for and with Indigenous peoples. This is a bold and necessary call in Indigenous suicide and prevention research-for us to become emboldened in our critical concern for addressing the complex forms of violence which make life unlivable, and to implicate our life in the pursuit of the type of justice that nourishes Indigenous life. 


\section{References}

Ansloos, J. P. (2017). The Medicine of Peace: Indigenous Youth Decolonizing Healing and Resisting Violence. Winnipeg, MB: Fernwood Publishing.

Ansloos, J. P. (2018). "To Speak in Our Own Ways About the World, Without Shame": Reflections on Indigenous Resurgence in Anti-Oppressive Research. In Creating Social Change Through Creativity (pp. 3-18). Palgrave Macmillan, Cham.

Badry, D., \& Felske, A. W. (2013). An examination of the social determinants of health as factors related to health, healing and prevention of fetal alcohol spectrum disorder in a northern context - the brightening our home fires project, Northwest Territories, Canada. International Journal of Circumpolar Health, 72. http://doi.org/10.3402/ijch.v72i0.21140

Billy-Ray Belcourt (2018) Meditations on reserve life, biosociality, and the taste of nonsovereignty, Settler Colonial Studies, 8(1), 1-15.

https://doi.org/10.1080/2201473X.2017.1279830

Berman, H., Mulcahy, G. A., Forchuk, C., Edmunds, K. A., Haldenby, A., \& Lopez, R. (2009). Uprooted and displaced: A critical narrative study of homeless, aboriginal, and newcomer girls in canada. Issues in Mental Health Nursing, 30(7), 418-430. https://doi.org/10.1080/01612840802624475

Royal Commission on Aboriginal Peoples. (1995). Choosing life: Special report on suicide among Aboriginal people. Canadian Government Publishing. Retrieved July 24, 2018, from https://lop.parl.ca/content/lop/researchpublications/mr131-e.htm

Canadian Broadcasting Corporation (CBC; 2018, March 19). Beyond 94: Where is Canada at with reconciliation? Retrieved July 27, 2018 from https://www.cbc.ca/news/indigenous/beyond-94truth-and-reconciliation-1.4574765

Canadian Psychological Association - Section for Indigenous Peoples Psychology (CPA-SIPP; 2018). Psychology's Response to the Truth and Reconciliation Commission of Canada's Report. Ottawa: Canadian Psychological Association. Retrieved July 27, 2018, from: https://www.cpa.ca/docs/File/Task_Forces/TRC\%20Task\%20Force\%20Report FINAL.pdf

Cavanagh, J. T. O., Carson, A. J., Sharpe, M., \& Lawrie, S. M. (2003). Psychological autopsy studies of suicide: A systematic review. Psychological Medicine, 33(3), 395-405. https://doi.org/10.1017/S0033291702006943

Chandler, M., \& Lalonde, C. (1998). Cultural continuity as a hedge against suicide in canada's first nations. Transcultural Psychiatry, 35(2), 191-219. https://doi.org/10.1177/136346159803500202

Chandler, M., \& Proulx, T. (2006). Changing selves in changing worlds: Youth suicide on the fault-lines of colliding cultures. Archives of Suicide Research, 10(2), 125-140. https://doi.org/10.1080/13811110600556707

Chilisa, B. (2011). Indigenous research methodologies. Sage Publications.

Colucci, E. (2006). The cultural facet of suicidal behaviour: Its importance and neglect. AeJAMH (Australian e-Journal for the Advancement of Mental Health), 5(3), 1-13. 


\section{http://dx.doi.org/10.5172/jamh.5.3.234}

Colucci, E., \& Lester, D. (Eds.). (2012). Suicide and culture: Understanding the context. Hogrefe Publishing.

Critical Suicide Studies Network. (2018, June 13). What is the Critical Suicide Studies Network? Retrieved July 30, 2018, from https://criticalsuicidology.net/what-is-critical-suicidology/

Crosby, A. \& Monaghan, J. (2018). Policing Indigenous Movements: Dissent and the Security State. Winnipeg, MB: Fernwood Publishing.

Cushman, P. (1995). Constructing the Self, Constructing America: A Cultural History Psychotherapy. Cambridge, MA: Da Capo Press.

Dell, C. A., Seguin, M., Hopkins, C., Tempier, R., Mehl-Madrona, L., Dell, D., ... Mosier, K. (2011). From Benzos to Berries: Treatment Offered at an Aboriginal Youth Solvent Abuse Treatment Centre Relays the Importance of Culture. The Canadian Journal of Psychiatry, 56(2), 75-83. https://doi.org/10.1177/070674371105600202

Durkalec, A., Furgal, C., Skinner, M. W., \& Sheldon, T. (2015). Climate change influences on environment as a determinant of Indigenous health: Relationships to place, sea ice, and health in an Inuit community. Social Science \& Medicine, 136-137, 17-26.

https://doi.org/10.1016/j.socscimed.2015.04.026

Elliott-Groves, E. (2018). Insights from Cowichan: A Hybrid Approach to Understanding Suicide in One First Nations' Collective. Suicide and Life-Threatening Behavior. https://doi.org/10.1111/sltb.12364

First Nations Mental Wellness Circle. (2014). First Nations Mental Wellness Continuum Framework. Vancouver. Thunderbird Partnership Foundation. Retrieved July 27, 2018, from: http://thunderbirdpf.org/first-nations-mental-wellness-continuum-framework/

Government of Canada. (2017). Breaking Point: The Suicide Crisis in Indigenous Communities: Report on the Standing Committee on Indigenous and Northern Affairs. Ottawa: Office of the Speaker of the House of Commons. Retrieved July 30, 2018, from: http://www.ourcommons.ca/Content/Committee/421/INAN/Reports/RP8977643/inanrp09/inanrp 09-e.pdf

Government of Canada. (2018). Suicide Prevention. Ottawa: Government of Canada-Health Canada. Retrieved July 26, 2018, from https://www.canada.ca/en/indigenous-servicescanada/services/first-nations-inuit-health/health-promotion/suicide-prevention.html

Haggarty, J. M., Cernovsky, Z., Bedard, M., \& Merskey, H. (2008). Suicidality in a Sample of Arctic Households. Suicide and Life-Threatening Behavior. 38, 699.

https://doi.org/10.1521/suli.2008.38.6.699

Hart, M. (2002). Seeking mino-pimatisiwin: An Aboriginal approach to helping. Fernwood Books Limited.

Health Canada (2013). National Aboriginal Youth Suicie Prevention Strategy (NAYSPS) Program Framework. Ottawa: Government of Canada, Ministry of Health. Retrieved July 27, 2018, from 
https://www.canada.ca/content/dam/hc-sc/migration/hc-sc/fniah-

spnia/alt formats/pdf/pubs/promotion/ suicide/strat-prev-youth-jeunes-eng.pdf

Hjelmeland, H. (2012). Suicide research and prevention: The importance of culture in "biological times" in Suicide and culture: Understanding the context by E. Colucci, D. Lester, H. Hjelmeland and B.C.B. Park (Eds.). pp. 3-18.

Hjelmeland, H., Dieserud, G., Dyregrov, K., Knizek, B. L., \& Leenaars, A. A. (2012). Psychological Autopsy Studies as Diagnostic Tools: Are They Methodologically Flawed? Death Studies, 36(7), 605-626. https://doi.org/10.1080/07481187.2011.584015

Hjelmeland, H., \& Knizek, B. L. (2017). Suicide and mental disorders: A discourse of politics, power, and vested interests. Death Studies, 41(8), 481-492.

https://doi.org/10.1080/07481187.2017.1332905

Hjelmeland, H., \& Knizek, B. L. (2016). Qualitative evidence in suicide: Findings from qualitative psychological autopsy studies. In Handbook of qualitative health research for evidence-based practice (pp. 355-371). Springer, New York, NY.

Huelin, R., Iheanacho, I., Payne, K. \& Sandman, K. (2015). What's in a Name? Systematic and NonSystematic Literature Reviews, and Why the Distinction Matters. New York: Evidera. Retrieved on September 19, 2018, from, https://www.evidera.com/wp-content/uploads/2015/06/Whats-ina-Name-Systematic-and-Non-Systematic-Literature-Reviews-and-Why-the-DistinctionMatters.pdf

Inuit Tapiriit Kanatami (2016). National Inuit Suicide Prevention Strategy. Ottawa: Inuit Tapiriit Kanatami. Retrieved July 22, 2018, from https://www.itk.ca/wp-content/uploads/2016/07/ITKNational-Inuit-Suicide-Prevention-Strategy-2016.pdf

Jaworski, K. (2014) The gender of suicide: Knowledge production, theory and suicidology. Burlington, VT: Ashgate Publishing Limited.

Kral, M. J. (1994). Suicide as Social Logic. Suicide and Life-Threatening Behavior, 24(3), 245-255. https://doi.org/10.1111/j.1943-278X.1994.tb00749.x

Kirmayer, L. J. (1994). Suicide Among Canadian Aboriginal Peoples. Transcultural Psychiatry, 31(1), 3-58. https://doi.org/10.1177/136346159403100101

Kovach, M. (2010). Indigenous methodologies: Characteristics, conversations, and contexts. University of Toronto Press.

Kumar, M. B., \& Nahwegahbow, A. (2016). Past-year suicidal thoughts among off-reserve First Nations, Métis and Inuit adults aged 18 to 25: Prevalence and associated characteristics. Statistics Canada. Retrieved September 19, 2018, from https://www150.statcan.gc.ca/n1/pub/89653-x/89-653-x2016011-eng.htm

Lee, E.V. (2016, November). In Defence of the Wastelands: A Survival Guide. Guts Magazine, 1(7). Retrieved July 27, 2018, from http://gutsmagazine.ca/wastelands/

Lemstra, M.E., Neudorf, C., Mackenbach, J., Kershaw, T., Nannapaneni, U., \& Scott, C., (2009). Suicidal ideation: the role of economic and Aboriginal cultural status after multivariate adjustment. Can. J. Psychiatry, 54, 589e595. https://doi.org/10.1177/070674370905400903 
Lemstra, M., Neudorf, C., Mackenbach, J., Kershaw, T., Nannapaneni, U., \& Scott, C. (2009). Suicidal ideation: The role of economic and aboriginal cultural status after multivariate

adjustment. Canadian Journal of Psychiatry, 54(9), 589-595.

https://doi.org/10.1177/070674370905400903

Maar, M. A., \& Shawande, M. (2010). Traditional Anishinabe Healing in a Clinical Setting. Journal of Aboriginal Health, 6, 18-27. Retrieved September 19, 2018 from, http://search.ebscohost.com/login.aspx?direct=true\&db=fph\&AN=51532485\&site=ehost-live

Marsh, I. (2010). Suicide: Foucault, history and truth. Cambridge University Press.

Million, D. (2013). Therapeutic nations: Healing in an age of indigenous human rights. University of Arizona Press

Mental Health Commission of Canada (2018). Suicide Prevention. Ottawa: Mental Health Commission of Canada. Retrieved July 27, 2018, from https:/www.mentalhealthcommission.ca/English/what-we-do/suicide-prevention

Nelson, S. E., \& Wilson, K. (2017). The mental health of Indigenous peoples in Canada: A critical review of research. Social Science \& Medicine, 176, 93-112. https://doi.org/10.1016/j.socscimed.2017.01.021

Offet-Gartner, K. (2011). Rewriting HerStory: Aboriginal women reclaim education as a tool for personal and community, health and well-being. Procedia - Social and Behavioral Sciences, 30, 1499-1506. https://doi.org/10.1016/j.sbspro.2011.10.290

Puchala, C., Paul, S., Kennedy, C., \& Mehl-Madrona, L. (2010). Using Traditional Spirituality to Reduce Domestic Violence Within Aboriginal Communities. The Journal of Alternative and Complementary Medicine, 16(1), 89-96. https://doi.org/10.1089/acm.2009.0213

Rogers, J. R., \& Soyka, K. M. (2004). “One size fits all”: An existential-constructivist perspective on the crisis intervention approach with suicidal individuals. Journal of Contemporary Psychotherapy, 34(1), 7-22. https://doi.org/10.1023/B:JOCP.0000010910.74165.3a

Shneidman, E. (1985). Definition of suicide. Northvale, NJ: Jason Aronson.

Simpson, A. (2014). Mohawk interruptus: Political life across the borders of settler states. Duke University Press.

Simpson, L. B. (2017). As we have always done: Indigenous freedom through radical resistance. University of Minnesota Press.

Smith, L. T. (2012). Decolonizing methodologies: Research and indigenous peoples. Zed Books Ltd. Snyder, M., \& Wilson, K. (2015). “Too much moving...there's always a reason”: understanding urban Aboriginal peoples' experiences of mobility and its impact on holistic health. Health Place 34, 181-189. http://dx.doi.org/10.1016/j.healthplace.2015.05.009.

Statistics Canada (2011). Aboriginal Peoples in Canada: First Nations People, Métis and Inuit. Ottawa: Statistics Canada. Retrieved July 25, 2018, from http:/www12.statcan.gc.ca/nhs-enm/2011/assa/99-011-x/99-011-x2011001-eng.pdf 
Statistics Canada (2012). Mortality rates among children and teenagers living in Inuit Nunangat, 1994 to 2008. Ottawa: Statistics Canada. Retrieved July 25, 2018, from https://www150.statcan.gc.ca/n1/en/pub/82-003-x/2012003/article/11695-eng.pdf?st=J7 xZdsK

Stewart, S. L. (2009). One Indigenous academic's evolution: A personal narrative of Native health research and competing ways of knowing. First Peoples Child \& Family Review, 4(1), 57-65. Retrieved July 27, 2018, from http://journals.sfu.ca/fpcfr/index.php/FPCFR/article/view/77

Tatz, C. (2012). Aborigines, sport and suicide. Sport in Society, 15(7), 922-93. https://doi.org/10.1080/17430437.2012.723352

Thomas, P., Bracken, P., \& Timimi, S. (2012). The limits of evidence-based medicine in psychiatry. Philosophy, Psychiatry, \& Psychology, 19(4), 295-308. https://doi.org/10.1353/ppp.2012.0058

Troian, M. (2018, March 27). Despite spending millions on prevention, feds don't keep track of suicide epidemic of Indigenous people (APTN Investigates, Ed.). Retrieved July 30, 2018, from http://aptnnews.ca/2018/03/27/despite-spending-millions-on-prevention-feds-dont-keep-track-ofsuicide-epidemic-of-indigenous-people/

Truth and Reconciliation Commission of Canada. (2015). Truth and Reconciliation Commission of Canada: Calls to Action. Ottawa: Government of Canada. Retrieved July 27, 2018, from http://nctr.ca/assets/reports/Calls to_Action_English2.pdf

Tuck, E., \& Yang, K. W. (2012). Decolonization is not a metaphor. Decolonization: Indigeneity, education \& society, 1(1). 1-40. https://jps.library.utoronto.ca/index.php/des/article/view/18630

Wexler, L. \& Gone, J. (2016). Exploring Possibilities for Indigenous Suicide Prevention: Responding to Cultural Understandings and Practices. In Critical Suicidology: Transforming Suicide Research and Prevention for the $21^{\text {st }}$ Century by J. White, I. Marsh, M.J. Kral, and J. Morris (Eds.). Vancouver: UBC Press.

White, J. (2017). What can critical suicidology do? Death Studies, 41(8), 472-480. https://doi.org/10.1080/07481187.2017.1332901

White, J. \& Mushquash, C. (2010). We belong: Life promotion to address Indigenous suicide. Thunderbird Partnership Foundation.

White, J., Marsh, 1. Kral, M.J., \& Morris, J. (2016). Critical Suicidology: Transforming Suicide Research and Prevention for the 21st Century.

World Health Organization. (2014). Preventing suicide: A global imperative. World Health Organization. Retrieved July 20, 2018, from http://www.who.int/mental health/suicideprevention/world_report_2014/en/

Wilson, S. (2008). Research is Ceremony: Indigenous Research Methods. Halifax, NS: Fernwood Publishing

Wingert, S. (2011). The social distribution of distress and well-being in the Canadian Aboriginal population living off reserve. International Indigenous Policy Journal, 2(1), 1-24. https://doi.org/10.18584/iipj.2011.2.1.4 


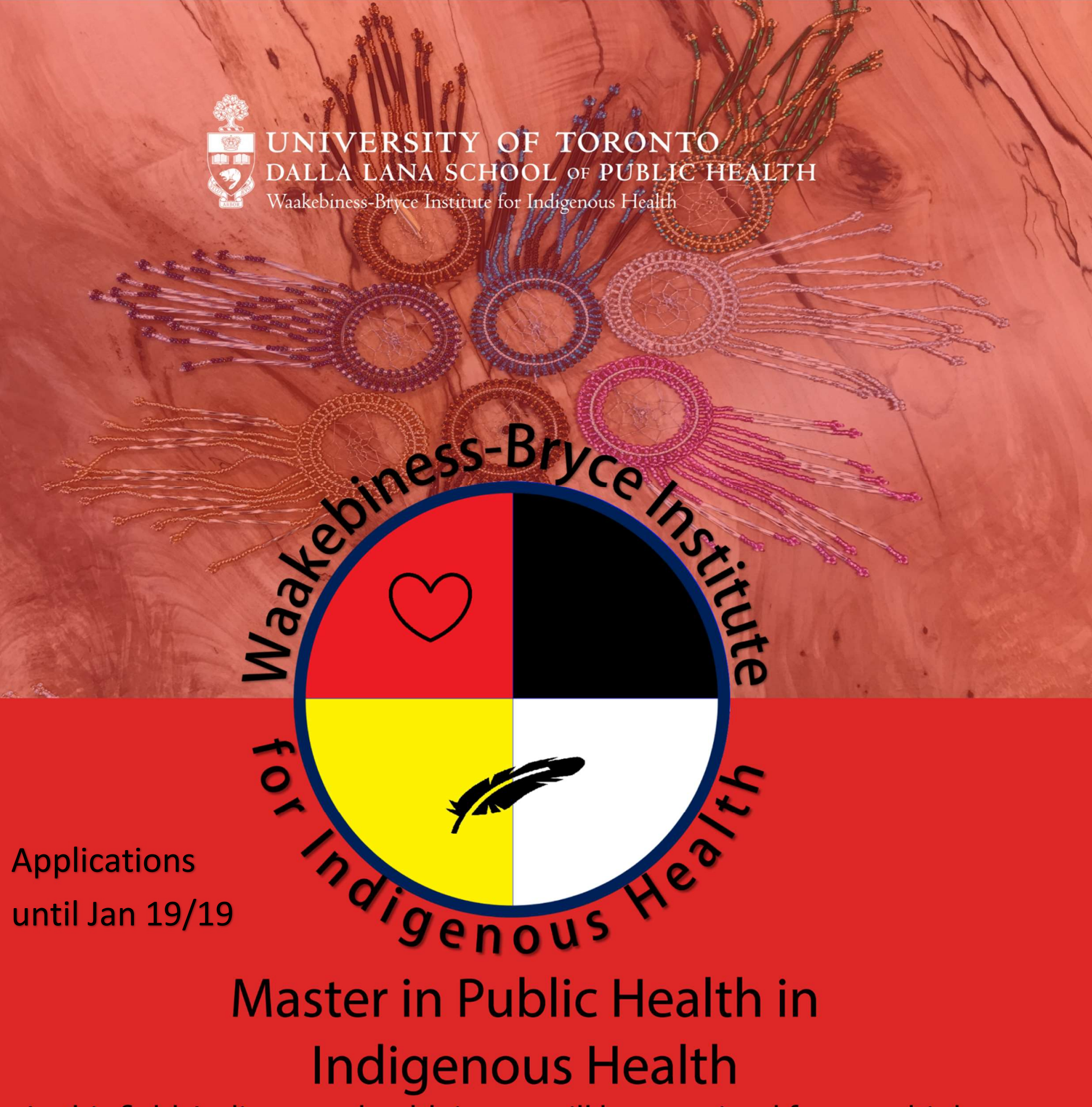

In this field, Indigenous health issues will be examined from multiple perspectives and world-views. Indigenous knowledges, pedagogies, and approaches to research will be utilized in tandem with Western approaches. Opportunities for land-based learning, traditional medicine teachings, interaction with Elders, and community engagement will permeate the program. Students will gain a broad public health knowledge base with specific expertise in Indigenous health issues.

Information:wbiih.dlsph@utoronto.ca 


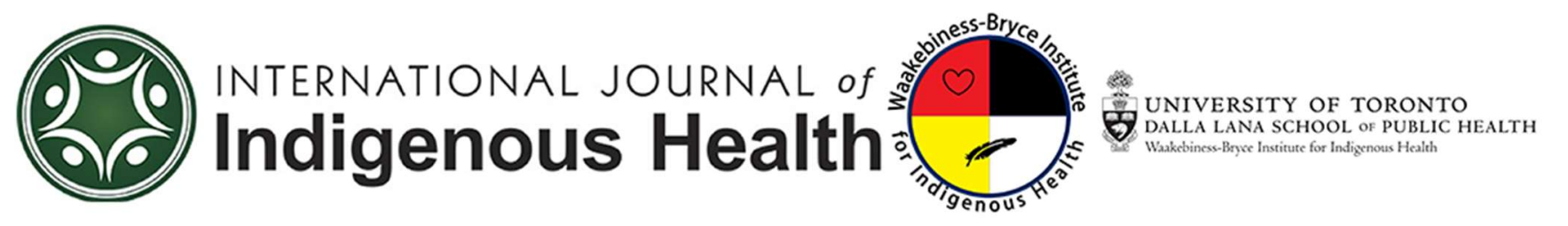

Volume 13

Issue 2. Death and Dying

Article 2

DOI 10.18357/ijih.v13i2.29749

December 2018

\section{Toku toa, he toa rangatira: A qualitative investigation of New Zealand Māori end-of- life care customs}

Tess Moeke-Maxwell, Dr.

Te Ārai Palliative Care and End of Life Research Group, School of Nursing, University of Auckland. t-moeke-maxwell@auckland.ac.nz

Rawiri Wharemate,

Te Ārai Palliative Care and End of Life Research Group, School of Nursing, University of Auckland.

r.wharemate@auckland.ac.nz

Stella Black,

Te Ārai Palliative Care and End of Life Research Group, School of Nursing, University of Auckland. stella.black@auckland.ac.nz

Kathleen Mason,

Te Ārai Palliative Care and End of Life Research Group, School of Nursing, University of Auckland.

k.mason@auckland.ac.nz

Janine Wiles, Associate Professor.

Social and Community Health, University of Auckland.

j.wiles@auckland.ac.nz

Merryn Gott, Professor.

Te Ārai Palliative Care and End of Life Research Group, School of Nursing, University of Auckland. m.gott@auckland.ac.nz

Follow the International Journal of Indigenous Health at:
https://jps.library.utoronto.ca/index.php/ijih/index

\section{Recommended Citation}

Moeke-Maxwell, T., Wharemate, R., Black, S., Mason,K., Wiles,J., Gott, M. (2018). Toku toa, he toa rangatira: A qualitative investigation of New Zealand Māori end-of-life care customs. IJIH13(2), 30-46.

DOI:10.18357/ijih.v13i2.29749 


\title{
Toku toa, he toa rangatira: A qualitative investigation of New Zealand Māori end-of-life care customs
}

\begin{abstract}
Informal end-of-life caregiving will increase over the next 30 years in line with the anticipated increase in older Māori deaths. Of concern, New Zealand's neo-colonial trajectory of loss of lands, cultural disenfranchisement, urban migration, ethnic diversity, global diaspora and changing whānau (family, including extended family) compositions has restricted some Indigenous whānau from retaining their end-of-life care customs. This article reports on a qualitative pilot study on Māori whānau end-of-life care customs undertaken to explore how those care customs contribute towards strengthening whānau resilience and bereavement. Five whānau, including 13 individuals from diverse iwi (tribes), took part in one of six face-to-face interviews. Kaupapa Māori research methods informed the analysis. The findings report a high level of customary caregiving knowledge among older whānau carers as well as a cohesive whānau collective support system for this group. Tribal care customs were handed down via 1) enculturation with tribal principles, processes and practices, 2) observing kaumātua processes and practices, and 3) being chosen and prepared for a specific care role by kaumātua. Younger participants had strong cultural care values but less customary care knowledge. The pilot concluded the need for a larger systematic qualitative study of Māori tikanga (customs) and kawa (guidelines) as well as the development of participant digital stories to support a free online educational resource to increase understanding among whānau, indigenous communities and the health and palliative care sectors.Indigenous suicide, Indigenous suicide prevention; Indigenous mental health; Critical suicidology; Indigenous youth suicide; Decolonizing methodologies; Suicidology; First Nations; Aboriginal; Indigenous health; Social determinants of health.
\end{abstract}

\section{Keywords}

Indigenous end-of-life care, Māori caregiving, palliative care.

\section{Creative Commons Licence (@) $\Theta \Theta \Theta$}

This work is licensed under a Creative Commons Attribution-Noncommercial-No Derivative Works 4.0 License. 


\section{Introduction}

The Indigenous proverb 'toku toa, he toa rangatira' ('my bravery is inherited from the chiefs of my forbears') highlights the cultural and spiritual legacies handed down from Māori tupuna (Māori ancestors) to their descendants to equip them to live and die well. Māori (Indigenous people of New Zealand) comprise 15 per cent of the total population (Statistics New Zealand, 2015) (approximately 4.5 million people). The cultural majority are predominately descendants of white British settlers. For Māori, birth and death are viewed as natural events that occur as part of the human life cycle. However, these ordinary life events are imbibed with extraordinary significance due to the heightened spiritual forces that are activated during these transitionary processes (Moeke-Maxwell \& Nikora, 2019). The preparation of the wairua (spirit) during older age and pre-death has great significance for Indigenous Māori. This is reflected in the pilot study's name, 'Pae Herenga', literally meaning the continuous movement of the spirit from before birth, during the time it inhabits its physical form and toward its journey home to the spirit realm.

End-of-life care, and the preparation of the spirit to leave its bodily form are primary functions of indigenous peoples (Duggleby et al., 2015). One of the great legacies from Māori tupuna is the belief in the spirit; it exists pre-birth before it takes up its home in the physical body and before it withdraws at the time of death whence it returns to the spiritual realm. The idea of the spirit transitioning between the metaphysical and physical realms is a core principle underpinning Māori health philosophy and practice, and by extension, end-of-life care and death care customs.

Pre-colonial caregiving customs involved practical processes and care rituals informed by 'tapu' (sanctity) and were underpinned by kawa (customary rituals) (Ngata, 2005) used by tohunga (priests and priestesses) in the treatment (cure) and comfort of the ill and dying. Chosen healers or people close to the ill or dying provided care in the final days of life (Brown, 1851; Dieffenbach, 1843; Hiroa, 1950). Death, like birth, involved the community. Spiritual processes and spiritual responses were needed to care for the ill and dying and to protect and preserve the community particularly as illness and death were often understood as emanating from spiritual transgressions. Heterogeneous tribes and diverse tribal customs meant there were variances among caregiving, dying and post-death rituals. Commonality prevailed in the belief of atua (gods), the spiritual realm and forces (Brown, 1851; Dieffenbach, 1843; Hiroa, 1950).

Many contemporary whānau (family, including extended family) continue to draw on their ancient cultural principles, processes and practices to care for the ill and dying (Ngata, 2005; Ministry of Health, 2001; Ministry of Social Development, 2008; Moeke-Maxwell, Nikora \& Te Awekotuku, 2013). However, the Te Ârai Palliative Care and End of Life Research Group's Kaumātua (Elders) are concerned that exposure to Western paradigms and urbanisation are influencing a change in traditional care patterns and practices, leading to a decrease in resilience among whānau involved in end-of-life care. They believe these cultural customs are a protective factor that support whānau to be resilient (Moeke-Maxwell, Nikora, \& Te Awekotuku, 2014) and need to be retained. Windle (2011) describes resilience within the end-of-life context as: 
... The process of negotiating, managing and adapting to significant sources of stress or trauma. Assets and resources within the individual, their life and environment facilitate this capacity for adaptation and 'bouncing back' in the face of adversity. Across the life course, the experience of resilience will vary (p. 152).

This article reports on the Pae Herenga pilot study undertaken to investigate Māori whānau endof-life care customs. The researchers are members of the Te Ārai Palliative Care and End of Life Research Group, School of Nursing, University of Auckland. We explored how Māori whānau care customs contribute towards strengthening whānau resilience and bereavement. The impetus for this study comes from the Te Ārai Palliative Care and End of Life Group's Kaumātua advisors (referred to hereafter as 'kaumātua'). Kaumātua prioritised the identification and collection of information about traditional care customs to support whānau carers with the increasing demands of end-of-life care (Giesbrecht, Wolse, Crooks \& Stajduhar, 2013). A further six key factors influenced Kaumātua to advocate for the study. Firstly, recent policy changes in NZ resulted in a shift in end-of-life care provision from the acute medical setting to community settings and placed greater responsibility on whānau to provide care within the home (Gott, Williams \& Moeke-Maxwell, 2014; Ministry of Health, 2017). Secondly, due to new medical treatments and pharmacological improvements aimed at prolonging life, whānau are often required to provide care over long periods of time placing stress on caregivers (Seymour \& Gott, 2011). Thirdly, there is an expected increase in older Māori deaths over the next thirty years, placing a high burden on whānau to provide end-of-life care (McLeod, 2016). A fourth factor concerns the difficulties whānau can have in accessing information about palliative care services and supports, something the Kaumātua recognised compounded the care burden (Kidd et al., 2014). A fifth factor reflected the high financial costs associated with care at end-of-life placing additional stress on whānau to cope at this challenging time (Gott, Williams, \& Moeke-Maxwell, 2014). Finally, current palliative care service delivery (e.g., hospice) is informed by policy and structural developments that draw from a Western understanding of 'a good death' and services may not always be congruent with the aspirations of Māori (Claire, 2005).

\section{Pae Herenga Research Methods}

\section{Pilot Aims}

The pilot aims were to investigate Māori whānau end-of-life care customs and to explore how those care customs contribute towards strengthening resilience and bereavement. The aim was to inform the design of a future larger study on this topic.

\section{Kaupapa Māori Research design (KMR)}

A 'by Māori with Māori' pilot study. A Kaupapa Māori Research (KMR) approach and ethnographic and qualitative research methods informed the study design (Bishop, 1996, 1999; Creswell, 2013; Mayring, 2015; The Pūtaiora Writing Group, 2010). KMR requires Māori involvement at every stage of the research process (The Pūtaiora Writing Group, 2010). A senior Māori researcher (TMM) worked with 
the Kaumātua to identify the research questions, collaborate on the research design and conduct fieldwork. Kaumātua helped to identify potential whānau to be interviewed via their community networks and they recruited participants. They also helped to lead two whānau interviews and contributed to a thematic analysis (Braun \& Clark, 2006) drawing on a KMR (The Pūtaiora Writing Group, 2010; Wiles, Rosenberg \& Kearns, 2005) and social constructivist analysis of the findings (Eketone, 2008). Kaumātua also identified knowledge translation pathways to distribute the research findings.

KMR: qualitative methods. Māori are an aural society. Therefore, a kanohi-ki-te-kanohi (face-to-face) data gathering method was employed to support whānau to tell their end-of-life caregiving stories (Bishop, 2005). This also allowed the researchers to carry out their cultural customs by providing manaaki (support, generosity, care) towards participants through incorporating time for whānaungatanga (relationships), karakia (prayers, chants, incantations), waiata (songs, singing), kai (food) and koha (gifts). Recruitment was via the Māori researcher (TMM) and Kaumātua community networks. Either face-to-face or telephone contact was made to invite the whānau participants into the study. A Letter of Invitation, Consent Form and Information Sheet were given to participants prior to their interview. At the start of each interview the research environment is normally charged with a lot of energy. Therefore, certain customary protocols are invoked (McKlintock, Mellsop, Moeke-Maxwell, \& Merry, 2010) to manage the high levels of energy that occur through the activation of wairua (spirit; spiritual forces; energies) that can occur between the living (researchers and participants) and their respective ancestors.

Each participant group was offered the opportunity to have a formal greeting at the start of their interview; some interviews included the following rituals while other participants requested some parts of this process: mihimihi (formal speeches); karakia, korerorero (talking/discussion), kai and after the interview, karakia, waiata and kai were also used to return the environment back to normal (discharge the high level of spiritual energy activated during the interview).

Koha (gifts) were taken to the interview premises; koha included gifts of food to contribute to the pōwhiri (formal greeting customs/process) and a gift voucher to acknowledge time spent in sharing story.

Whānau participants. Six interviews were conducted with five whānau who took part in a one-off interview, including 13 individuals with multiple caregiving experiences. Whānau represented the iwi (tribe) of Ngāpuhi, Tainui, Ngāti Porou, and Te Arawa. Five interviews took place in Auckland, and one in Rotorua. Three interviews took place at the carer's private home. Two further interviews took place in a work environment, and one in a café.

Participant data. Face-to-face interviews were conducted in English and Te Reo Māori (Māori language) using open-ended questions. Each interview was digitally recorded and transcribed. A third koha included the gift of a summary report. Summary reports are a form of negotiated member checking (Birt et al, 2016) using a Collaborative Story Production (CSP) method (Bishop, 1996; Moeke-Maxwell, Wiles, Black, Williams, \& Gott, 2018). The summary reports summarised key information as shared by the participant whānau. Whānau had an opportunity to take part in the CSP member checking method; 
they could make changes, amend or delete content in their summary report (story) they were not happy with.

\section{Tikanga (customs) and kawa (guidelines)}

\section{Findings}

This section sets out the tikanga and kawa that Māori employed to care for their whānau at endof-life. Care was often reciprocal. For example, the ill person needed to know that things were in place to care for their whānau and iwi after they had gone:

...when she was dying, my mum was dying, she said to me 'the most important gift you kids can give to me is to keep together, be good to each other, accept each other's idiosyncrasies, and make sure that you keep up the mana [status, authority and prestige] of the things of the tupuna.' (Ngawai, daughter).

Depending on their level of health, the ill person was an active participant in their end-of-life journey. They provided instructions on care preferences, helped to organise their funerals. as well as visited ancestral homes and other places of whānau or tribal significance in preparation for their passing. They participated in whānau/tribal meetings, passed on whakapapa (genealogy) knowledge, and named babies before they died. Wise counsel was given to whānau members on how to lead their lives. Rewi commented:

Those two years, all those weekends that we had with each other, it was a time for each and every one of us to really spend quality time with our mum... How it helped her? It helped her like to prepare us; you know how sometimes they say that some of them don't go on really peacefully because there's unfinished business. And our mother, I honestly believe that with every single one of us she brought us up to a point where it was like acceptance.

A range of cultural principles, practices and processes supported whānau to provide end-of-life care, often over long periods of time. For example, karakia, kai rangatira (special foods given to esteemed people such as, sea urchins, crayfish and other favorite food items), kotahitanga (collective decision making processes), wairuatanga (spirituality), whanaungatanga (relationships/sense of connection), and tribal values informed and strengthened caregiving practices.

Whānau were pivotal in supporting the ill person to live longer. They helped them to fulfill their cultural and familial obligations and achieve their end-of-life preferences. Daughter Kuini expressed, "as a whole, our overall care should be one that would in the end bring us back together or hold us together, and bring Mum some satisfaction, so that when she's gone, she would know that we would be okay as a whānau."

Ensuring the ill person's wairua felt peaceful was a priority. Whānau helped the ill person to complete things; for example, it was important for a kuia to complete a book of her tribal whakapapa 
before she died. Companionship was provided 24 hours a day; this enabled the ill person to be listened to as they reflected on their past. Rewi, an older son, commented:

I say this having been involved with a lot of the old people, those are the things that keep them alive at the end of the day, those memories of home, of associations, of tikang $\bar{a}$, of great men and great women who have been influential in their lives... [When you go back and say], 'You remember Granny so and so?' [and they reply] 'Oh that old fella?' and away they go [reminiscing]. So, for us, it's not just bringing back the old memories; but what it is, is almost a rest in peace process really and a levelling of a peaceful wairua for all of $u s \ldots$

\section{Whanaungatanga (relationships and connections)}

Whānau who appeared to have a high level of tikanga and kawa were able to carry out a collective whānau system of care. Whānau members returned home upon hearing news of a life limiting diagnosis. For one person, this meant leaving their Australian home to provide care to an ill mother for two years. Care was sustainable because it utilised the collective strengths and resources (including, financial) of the whole whānau. Rewi expressed that the "observance of tikanga" ensured that "islands within the family" were avoided.

Hui (tribal and whānau gatherings) allowed space for discussion and unified decision-making. The very act of being together and sharing the care responsibility strengthened whānau. Whānau made the most of their time with their loved one before they died, particularly if the person was a prominent figure in their iwi; they knew that "handing over" the deceased to "the people" [tribe] for the tangihanga (customary funeral rituals) would take priority following their death.

\section{Aroha (love, concern, empathy)}

The obligation embedded within the cultural principles, processes, and practices of aroha (love, concern, empathy) ensured whānau protected the dying person before and after death. Irihapeti used a spirit of enquiry with her mother (a gentle way of communicating with her about her needs) to ensure her mana was kept intact and her mauri (life force) was preserved. Maia, a younger female carer, described the empathic care she gave her father-in-law:

...so, at the beginning I had to move in slowly, gain his trust, get to know who I am and then I had to learn about [him] and then we can slowly-and then I find out what he likes, the things that makes him happy, and that's like sports and that. [Dementia] it's like a baby being born, being a child, then being a lady... and then a nana and you're going back down... you end up being a baby again, so you've got to nurture them like when they were a baby. That's how I treated 
him. It got to the stage of him calling me 'Mum', because he knows what I was doing for him is what his mum would do for him.

Aroha strengthened whānau to help the dying person's wairua prepare for its transition; for example, encouraging them to "let go" was thought to help them release their wairua from the physical form. Karakia were offered, and waiata were sung to help the dying process. Encouraging words to support the dying process were also spoken by the young:

[My sister] looked up a couple of times and it was just her mokopuna [grandchild], her grandson; he would be seven or eight and he came in, and he came skipping in, and he said 'Nani's [Grandma's] going to go soon.' [He] came in a little boy, skipped up next to his nan, gave her a kiss. Um, and he went out and he got his mum and he says 'I think you had better come in now. Nan's going'. He said it so innocently, how kiddies do.

\section{Wairuatanga (spirituality)}

Older participants reflected on tribal responses to illness and dying. Kura, an older kuia, said:

Again old age; there was no such thing as sickness; it was never seen as sickness. If it was, it was probably more mākutu [spiritual curses]; i.e. they had done something wrong and we hadn't experienced anything like that [Western idea of sickness]; if it was there it was never talked about.

Participants observed different forms of spirituality including Christianity. Spiritual beliefs and practices fortified the ill person and their whānau. Daughter Kaea, recalled her mother using her faith to control her pain:

When I was at the hospital with her I said, 'oh Mum why don't you just go to sleep?' And she said, 'Jesus suffered', that's all I needed to hear. 'Jesus suffered', that's all she said. I'm crying my eyes out for her. That's what she's like.

Spiritual principles, processes and practices underpinned everything whānau did to help alleviate suffering and maintain the mauri of the ill and dying. Upholding their mana until their spirit successfully transitioned across the ārai (veil) revealed a deeply meaningful cultural obligation. The dying person was never left on their own before or after death as whānau believed that feeling safe and loved would help them to transition. Ngawai reflected on her sister's death, "we were all there, she slipped away, and we were singing, 'Can I have this dance for the rest of my life.' That one: 'I had the last waltz with you,' and of course that's what our dad used to sing."

Spiritual principles guided decision-making processes, end-of-life care practices and post-death care. Rituals were utilised for specific care domains: care of the tinana (body), care of the hinengaro (mind/emotions), care of the wairua, care of the whānau, care of the kaingā (home) and preparation of the post-death setting (marae; ancestral meeting house) where the body would lie in state before burial. 
The gathering and preparing of food and drink, for example, and the preparation and application of rongoā Māori (plant medicines) and holistic care, are all attributable to care of the tinana, but were treated as deeply spiritual practices. Kura reflected on how her ancestors prepared themselves to die:

... our old people, they know when they're going to die, because they're getting messages. They know, and the first visible sign is that they will stop eating. The first thing we do [today] is shove [food] into them don't we? That's the first sign. Absolutely, and doctors too will say "you've got to eat", that's totally against the grain. And they know when they're going to go because the spiritual world are telling them so. It comes in different ways and it's fasting, it's straight out fasting. And what that does... they are clearing the body... that is very, very important as well to be aware of what nature is doing... [rongoā] all helps to clear the passages right through and the fasting clears the tract, the oesophagus - it clears the whole tract so that the [body is cleared].... Our people didn't have that [embalming chemicals] but they went into fasting to clear all of that, to make it a lot easier for their passing and also for their caring. It was a two-way process and so we get back to the manuka [native plant] again; it's one example of rongoa that was burnt to help with all of that.

The dying received tohu (messages from the spiritual realm) through visions, signs or dreams; it was common for them to see deceased relatives. Their dreams brought confidence, comfort and encouragement in times of vulnerability. Intuitiveness increased in the dying person as death drew closer; Irihapeti said "[Mum] was very intuitive with her wairua; she always knew, she had a knowing about her." Intuitiveness also increased in whānau. Spiritual phenomena were viewed as a normal part of living at end-of-life. Irihapeti reflected:

[We] always wanted to know how she was, and asked her 'did she feel like this?

What she wanted? How was your sleep, and why are you dreaming?' She had lots of dreams... She always had dreams... And she often saw those who had already passed on.

Spiritual signs signaled the spirit's transition. However not all spiritual signs were welcome, despite them offering a protective warning. Daughter Moana reflected:

$[W]$ e slept at the house at night... my dad was waiting for my whāngai [adopted] brother to come out of the bush. He came out of the bush and he sat down in the bedroom with my dad in a rocking chair. And I was asleep in the lounge; it must have been about 10 or 11 at night and we heard this almighty thumping on our front door, it nearly broke the door off its hinges. And I got up and my chest was pounding. My brother came running down the hall; we ripped open the door, and there was no one there. When my mother got home... we told her and she goes 'did you invite all of your [deceased] aunties and uncles and did you say 'here he is come and take him when you're ready?' And that's what it was. That was a tohu [sign]. I'd never experienced it before in my life extremely powerful. So, they came knocking and my brother and I both knew what it meant and so we shut the door very quickly because we didn't want 
anyone to come in and take him. We slammed the door shut and I remember going back to bed and my heart pounding because I knew they were coming. And he passed away the next night around that time... Yes it was as if they were coming to say 'we're coming'.

\section{Variations in Māori language, enculturation and care customs}

Participants described variances in care customs highlighting the diversity between, and within, whānau. The majority of interviewees $(n=10)$, had a higher level of te reo Māori (Māori language) and traditional enculturation, in comparison to a smaller group of participants $(n=3)$. The 'traditional' group had either observed their Elders providing end-of-life care or they were nurtured with specific skills by their parents and grandparents who recognised their strengths. In contrast, the second group of less traditional whānau had less language proficiency and less cultural knowledge and end-of-life care experience.

The traditional group often comprised large whānau who were well connected enabling a rich collective of whānau carers, often with assigned 'care' roles. For example, Moana said her role was to liaise with her father, who was a prominent member of his iwi, about manuhiri (visitors) who sought an audience with the chief before he died:

[Before he died] I was weaving the threads, constantly weaving, watching, where's this thread [manuhiri/visitor connection] coming from, is it the right thread? I remember people turning up, expecting to get an audience with my father and someone had brought them, a whanaunga [relative] had brought them, and based on that they were [a public celebrity but someone my father did not know personally], I should give them access to my father. Already I knew 'oh...that's wrong'. I went down to Father and I said to him 'Dad so and so's here'- No, I knew, I knew they wouldn't get access to him; I knew. He taught me that valuable lesson about acting from a position of tika [truth; correctness] pono [honesty; sincerity] and aroha.

The traditional care group had in-depth knowledge of wairuatanga. Spiritual practices were drawn on by elders to reduce physical pain, for example. Karakia and waiata were common practices employed to bring relief from physical suffering. Taking older people to visit a beloved ancestral home or tūrangawaewae (place of significance) was another form of spiritual practice that eased the emotions and settled the wairua, particularly before death.

Gendered care roles were observed among the traditional group. Men tended to carry out the spiritual care rituals. For example, Rewi spoke about how he and his brothers fasted to ensure their karakia were tika (correct); karakia had to be strong enough to support their ill mother through her endof-life journey and death transition. Men were responsible for gathering special foods (kai rangatira) to support hosting manuhiri (guests) who visited the ill person before death and also at tangihanga 
(funerals). Women tended to provide personal and intimate care; they also administered medications and oversaw the domestic care setting.

The 'less traditional' group of carers appeared to have strong cultural values which supported them to undertake care; aroha, manaakitanga, whanaungatanga and rangatiratanga [leadership] were some of the core values identified. These dedicated carers provided the bulk of end-of-life and postdeath care. Typically, care was carried out by a primary carer supported by a spouse, or, one or two siblings. These carers tended to be younger and, to some extent, not as connected to their tribal collectives. As the ill person drew closer to death more whānau members would gather to provide support to the dying person. It was often hard for less connected carers to access support from other family members earlier. Daughter Ana reflected on the disconnection within her own whānau:

Because, Dad as such, he wasn't that close with the whannau. And then on Mum's side of the whānau, well they didn't like Dad in a sense... because Dad married their Queenie and so of course Mum's brother was, he was there, but I just felt like I couldn't talk to [him] either. I don't know, I got in [to] this thing that 'oh well it's just you and me Dad'.

Having whānau support was critical at the end of life. Maia explained:

I asked [my whānau] ... when Dad was in hospital, before I brought him home for those eight days, I begged... 'I need one of you [here], because I don't want to be alone when he goes'. So, I had [name of female relative] with me and then [name of male relative] happened to appear the day he passed away.

Heterogeneous whānau often had different values, leading to problems with planning, decisionmaking and carrying out end-of-life and post-death care. For example, Ngawai reflected on the crosscultural issues her whānau experienced when their sister, who was married to a man from a different cultural background, was nearing the end of her life. Differences in cultural values and personal end-oflife care preferences made it extremely difficult for Ngawai's Māori whānau to care for their dying sister in the way they wanted:

... when she was dying, I asked him [brother in law] if we'd put [sister] in the lounge, 'oh no, I want to sleep by my wife - I've slept with her for the last blah, blah, blah, blah'... and so that made it really difficult. We were squashed up in the corner asleep on the armchair ... It would have created more space; we could have all slept around there with her on the sofas ... it would have been like how we did it with our mum. And our mum was in the middle of the lounge and everybody was there. And then to make matters worse, he would put the TV on when we're singing, even when we were doing the church, he put the TV on. I said, 'do you mind?' like that type of ignorance. As far as the strength, where did the strength come from? If my mum hadn't have taught us well, we could have quite easily been had up for murder.

Furthermore, Ngawai's sister was cremated according to her brother-in-laws wishes, a practice that has traditionally been avoided among Māori until recently. 


\section{Transmission of care customs among whānau with high enculturation}

Care roles and specific tasks were assigned to individuals by their Elders. These roles were based on the individual's status within the whānau, reflecting either a tuākana (older sibling) or tēina (younger sibling) relationship position. They were also based on the individual's strengths, often identified during childhood. Strong tribal and whānau values were drawn on to provide end-of-life care such as aroha, whānaungatanga, manaakitanga, kotahitanga (unity; consensus decision-making), rangatiratanga and wairuatanga. Whānau who appeared to have a high level of knowledge and experience using their traditional end-of-life care customs acquired this mātauranga (indigenous Māori knowledge) in two inter-connected ways; through kaitiakitanga (guardianship/stewardship) and role-modeling.

Kaitiakitanga (guardianship/stewardship) was an important component in the whānau care structure. In terms of social care, the kaitiakitanga role was often informed by the wairua of an individual. The right āhua (character/nature) was needed to do a particular job. For example, providing personal care and companionship, attending to the social aspects of care and spiritual care required people with specific skills. The findings revealed that individuals knew their roles, and each contributed to a 'whole system' of care. The system was collaborative and inclusive of older people, whānau and community, and was informed by wairua forces.

Whānau carers learned about their traditional care customs through observing parents, grandparents and other relatives performing specific care roles within the end-of-life context. Closely related to this was the cultural preparation some individuals received to equip them to undertake a specific care role. This helped them to prepare for the time when they would assume an aspect of care responsibility as part of the collective whānau system. Rewi, who had in-depth knowledge of te reo Māori, tikanga and kawa reflected:

I find that 'whakamarama' is better than saying 'well this is what I know or understand.' Whakamarama is a good korero term because 'marama' means light; it means the moon. So when you korero [talk] there is a communication of light between Te Atua [Creator] and down here. Then you turn and you say 'na reira e karanga hoki te aka matua ki konei.' As a boy, the explanation I was given about this is that there is an umbilical cord or the toto that comes from the heavens that come down ... into Papatūānuku [Earth Mother]. And the umbilical cord, the toto that comes from God down to the earth, feeds all creation. For us the toto is wairua ... we have a literal feeling from [the Creator] to us through the aka matua which is a vine.

\section{Best method for future study}

All participants identified that there is a need for whānau to be supported and culturally resourced to provide end-of-life care, particularly for diverse or smaller whānau. Participants want the health and palliative care sector's knowledge and understanding of traditional care customs to increase to benefit whānau service users. 
Given the sensitive nature of the research subject and the bereaved status of research participants, there was an overwhelming response to collect information using KMR principles employing face-toface interviews. Pae Herenga pilot participants strongly recommended that the digital storytelling method be used to collect qualitative information on traditional caregiving. Just prior to being interviewed, six older participants had successfully participated in a digital storytelling project on endof-life care. The digital storytelling method was thought to be a viable tool for stimulating conversation about end-of-life caregiving experiences for Māori. The best method for conducting a larger Pae Herenga study was discussed by Rewi and his sister Kuini:

Rewi: I think that because it's a very personal journey that [the data collection] needs to be in a home where they're comfortable and they have the power to make the choices about how this whole thing goes.

Kuini: Yes, excellent... Having the digital story up front [is] a good way to focus on the initial story or feelings and then coming back to a discussion like this is actually good [as it] then can give it the depth.

\section{Limitations}

The pilot study was primarily conducted in one large urban North Island city, with one interview being conducted in a smaller urban North Island city. As such, it excluded the experiences and perspectives of rurally based whānau (who may have been more likely to have retained their traditional care customs), whānau residing in urban townships and those living in the South Island.

A further limitation was the lower level of enculturation among three of the 13 interviewees resulting in fewer cultural care experiences to examine. While this was a limitation it helpfully highlighted the importance of inter-generational transference of cultural care knowledge customs for Māori carers.

\section{Concluding comment}

Previous research indicates Indigenous cultural and spiritual customs are protective (Duggleby et al., 2015; Ministry of Health, 2001; Moeke-Maxwell, 2014; Moeke-Maxwell et al., 2013a, 2015). An investigation of traditional Māori care customs was considered critical to gather evidence on the link between resilience and traditional end-of-life care customs, itself an under-researched area. The findings highlight that customary caregiving knowledge strengthened whānau to provide end-of-life care. Traditional holistic end-of-life care customs prepared and fortified whānau to provide care throughout the illness-death-tangihanga trajectory. The depth and level of this cultural care was more likely to be held and practiced by whānau who had received cultural mentoring from their tūpuna and who had a high proficiency in te reo Māori, tikanga and kawa. Whānau with less mātauranga Māori upheld the key principles of care demonstrated in their cultural values but were less supported by extended family, therefore they did not benefit as much from the collective care system. 
The findings further highlight that Māori whānau are heterogeneous, and care customs can vary from iwi to iwi and from whānau to whānau. The impact of neo-colonial forces (loss of lands, 'urban drift,' cultural disenfranchisement, global diaspora, ethnic diversity, changing whānau compositions) and living in te ao hurihuri (the changing world) (Gott et. al, 2015; Moeke-Maxwell, 2016; Moeke-Maxwell et al., 2014; Reid, 2005) affect the ability of whānau to retain their traditional care giving customs.

The pilot findings identified that there are some specific cultural practices that helped to strengthen and guide whānau carers. A larger Kaupapa Māori Research study would undertake a systematic collection of qualitative data on traditional care customs to support the end-of-life caregiving activities of whānau. The development of a free, online educational resource, such as digital stories, could help to strengthen whānau who are increasingly being called upon to provide end-of-life care to meet the growing palliative care demand of older people (Moeke-Maxwell, 2014; Moeke-Maxwell, Nikora, \& Te Awekotuku, 2013a; 2015). Access to cultural care information would help to strengthen carer resilience and care sustainability among diverse carers (Moeke-Maxwell, Nikora, \& Te Awekotuku, 2014) by preserving mātauranga (cultural knowledge) on end-of-life care customs. It is critical that whānau are well supported to care for their ill and dying, particularly when it involves the care and protection of the most vulnerable, the oldest old. Maia, a young woman who cared for her father-in-law, highlights that indigenous end-of-life care is deeply relational and is driven by aroha:

Having Dad, it's made me stronger; it's helped me more [or] just as much as I've helped him. Because of his age, being elderly, us as carers, should look at how much more time they've got left and try and make it the best for them. It should be all about them because you [carers] have your own time once they're passed on, because they're not there for long. There's only one more place they go to after being old, and Dad, he knew his time was coming, and I knew his time was coming. And all I could do was just keep on loving him and being there, not leaving him alone - they don't like being alone. It's a lonely world when you're old.

\section{References}

Birt, L., Scott, S., Cavers, D., Campbell, C. \& Walter, F. (2016). Member checking: A tool to enhance Trustworthiness of merely a nod to validation? Qualitative Health Research 26(13), 1802-1811. https://doi.org/10:10.1177/10497323I6654

Bishop, R. (1996). Collaborative storytelling: meeting indigenous peoples' desires for selfdetermination in research. Paper; Meeting of Indigenous education around the world: workshop papers from the world indigenous people's conference. June. Albuquerque: New Mexico.

Bishop, R. (1999). Kaupapa Māori research: an indigenous approach to creating knowledge. In L. Nikora, \& N. Robertson (Eds.), Māori psychology: Research and practice (pp. 1-6). 
Hamilton, New Zealand: Department of Psychology, University of Waikato.

Bishop, R. (2005). Freeing ourselves from neo-colonial domination in research: A Kaupapa Maori approach to creating knowledge. In N. Denzin \& Y. Lincoln (Eds.), The Sage handbook of qualitative research (3rd ed., pp. 109-239). Thousand Oaks, CA: Sage.

Braun, V. \& Clarke, V. (2006). Using thematic analysis in psychology. Qualitative Research in Psychology, 3(2), 77-10. http://dx.doi.org/10.1191/1478088706qp063oa

Brown, W. (1851). New Zealand and its Aborigine. J. \& D.A. Darling.

Claire, S. (2005). Contemporary perspectives. In M. Schwass (ed.), Last words: Approaches to death in New Zealand's cultures and faiths (pp.41-47). Wellington, New Zealand: Bridgett Williams Books with the Funeral Directors Association of New Zealand.

Creswell, J. W. (2013). Qualitative inquiry and research design: choosing among five approaches (3rd ed). Los Angeles: SAGE Publications.

Dieffenbach, E. (1843). Travels in New Zealand: With contributions to the geography, botany, and natural history of that country (Vol. 2). London: John Murray.

Duggleby, W., Kuchera, S., McLeod, R., Holyoke, P., Scott, T., Holtslander, L., . . Chambers, T. (2015). Indigenous people's experiences at the end of life. Palliative \& Supportive Care, 13, 1721-1733. https://doi.org/10.1017/S147895151500070X

Durie, M. (1994). Whaiora: Māori health development. Auckland, New Zealand: Oxford University Press.

Eketone, A. (2008). Theoretical underpinning of kaupapa Māori directed practice. MAI Review, $1,1-3$.

Giesbrecht, M., Wolse, F., Crooks, V.A., \& Stajduhar, K. (2014). Identifying socioenvironmental factors that facilitate resilience among Canadian palliative family caregivers: A qualitative case study. Palliative and Supportive Care, 12(4), 111. https://doi.org/10.1017/S1478951513001028.

Gott, M., Moeke-Maxwell, T., Williams, L., Black, S., Trussardi, G., Wiles, J., . . Kerse, N. (2015). Te Pakeketanga: living and dying in advanced age--a study protocol. $B M C$ Palliative Care, 14(74), 21. https://doi.org/10.1186/s12904-015-0073-4.

Gott, M., Williams, L., \& Moeke-Maxwell, T. (2014). The paradoxes of 'home' within a palliative care context. In M. Roche, R. Mansvelt, R. Prince, \& A. Gallagher (Eds.), Engaging geographies: Landscapes, lifecourses and mobilities (pp. 137-151). Cambridge: Cambridge University Press.

Hiroa, T. R. (1950). The coming of the Maori. Wellington: Thomas Avery \& Sons.

Kidd, J., Reid, S., Collins, N., Gibbons, V., Black, S., Blundell, R., . . Ahu, H. (2014). Kia mau te kahu whakamaru: Health literacy in palliative care. Wellington, New Zealand: Ministry of Health.

Mayring, P. (2015). Qualitative Content Analysis: Theoretical Background and Procedures Approaches to Qualitative Research in Mathematics Education Springer. 365-380.

McClintock, K., Mellsop, G., Moeke-Maxwell, T., \& Merry, S. (2010). Pōwhiri process in 
mental health research. International Journal of Social Psychiatry, Online, 1-

2. https://doi.org/10.1177/0020764010387067

McLeod, H. (2016).'The need for palliative care in New Zealand. Technical report prepared for the Ministry of Health.

Ministry of Health. (2001). The New Zealand Palliative Care Strategy. Wellington, New Zealand: Author.

Ministry of Health. (2017). Palliative Care Action Plan. Wellington, New Zealand: Author.

Ministry of Social Development. (2008). The New Zealand carers' strategy and five-year action plan 2008. Wellington, New Zealand: Author.

Moeke-Maxwell, T. (2016). He wāhine āwhina: a healing narrative of end of life care. In W. Waiatoki, M. Levy (Eds.) Te manu kai i te mātauranga : indigenous psychology in Aotearoa/New Zealand. Wellington, New Zealand: New Zealand Psychological Association.

Moeke-Maxwell, T., \& Nikora, L.W. (2019). Wairua Manuake - Flight of the Wairua: Māori end of life preparations. Publication pending.

Moeke-Maxwell, T., Nikora, L. W., \& Te Awekotuku, N. (2013). Manaakitanga: Ethical research with Māori who are dying. In M. Agee, T. McIntosh, P. Culbertson, \& C. Makasiale (Eds.), Pacific identities and well-being - Cross-cultural perspectives (pp. 188203). London: Routledge.

Moeke-Maxwell, T., Nikora, L. W., \& Te Awekotuku, N. (2014). End-of-life care and Māori Whānau Resilience. Mai Journal, 3(2), 140-152. Retrieved from: http://www.journal.mai.ac.nz/sites/default/files/MAI_Jrnl_V3_iss2_Maxwell.pdf

Moeke-Maxwell, T., Nikora, L. W., \& Te Awekotuku, N. (2015). Homedeathscapes: Māori endof-life decision-making processes. In M. Kepa, M. McPherson, \& L. Manu'atu (Eds.), Home: Here to stay. Wellington, New Zealand: Huia.

Moeke-Maxwell, T., Wiles, J., Black, S., Williams, L., \& Gott, M. (2018). Collaborative Story Production with bereaved family carers of people who died in advanced age. Qualitative Research Journal - publication pending. 30 June 2018.

Ngata, P. (2005). Death, dying and grief. In M. Schwass (ed.), Last words: Approaches to death in New Zealand's cultures and faiths (pp. 29-41). Wellington: Bridgett Williams Books with the Funeral Directors Association of New Zealand.

Reid, P. (2005). Contemporary perspectives. In M. Schwass (Ed.), Last words: Approaches to death in New Zealand's cultures and faiths (pp. 41-49). Wellington: Bridgett Williams Books with the Funeral Directors Association of New Zealand.

Seymour, J., \& Gott, M. (2011). The challenges of health technology for ageing and dying. In M. Gott, \& C. Ingleton (Eds.), Living with ageing and dying: palliative and end of life care for older people (pp. 42-51). Oxford: Oxford University Press.

Statistics New Zealand. (2015). Major ethnic groups in New Zealand. Retrieved from https://www.stats.govt.nz/infographics/major-ethnic-groups-in-new-zealand 
The Pūtaiora Writing Group. (2010). Guidelines for Māori Research Ethics: A Framework for Researchers and Ethics Committee Members. Auckland, New Zealand: Health Research Council.

Wiles, J.L., Rosenberg, M.W., \& Kearns, R.A. (2005). Narrative analysis as a strategy for understanding interview talk in geographic research. Area, 37, 89-99.

Williams, L., Moeke-Maxwell, T., Kothari, S., Pearson, S., Gott, M., Black, S., \& Hansen, W. (2015). Is digital storytelling ka pai for New Zealand Māori? Using digital storytelling as a method to explore whānau end of life caregiving experiences: a pilot study. $B M J$ supportive \& palliative care, 5(Suppl 1), 23.

Windle, G. (2011). What is resilience? A review and concept analysis. Reviews in Clinical Gerontology, 21, 152-169. https://doi.org/10.1017/S0959259810000420 


\section{WAAKEBINESS-BRYCE INSTITUTE FOR INDIGENOUS HEALTH}

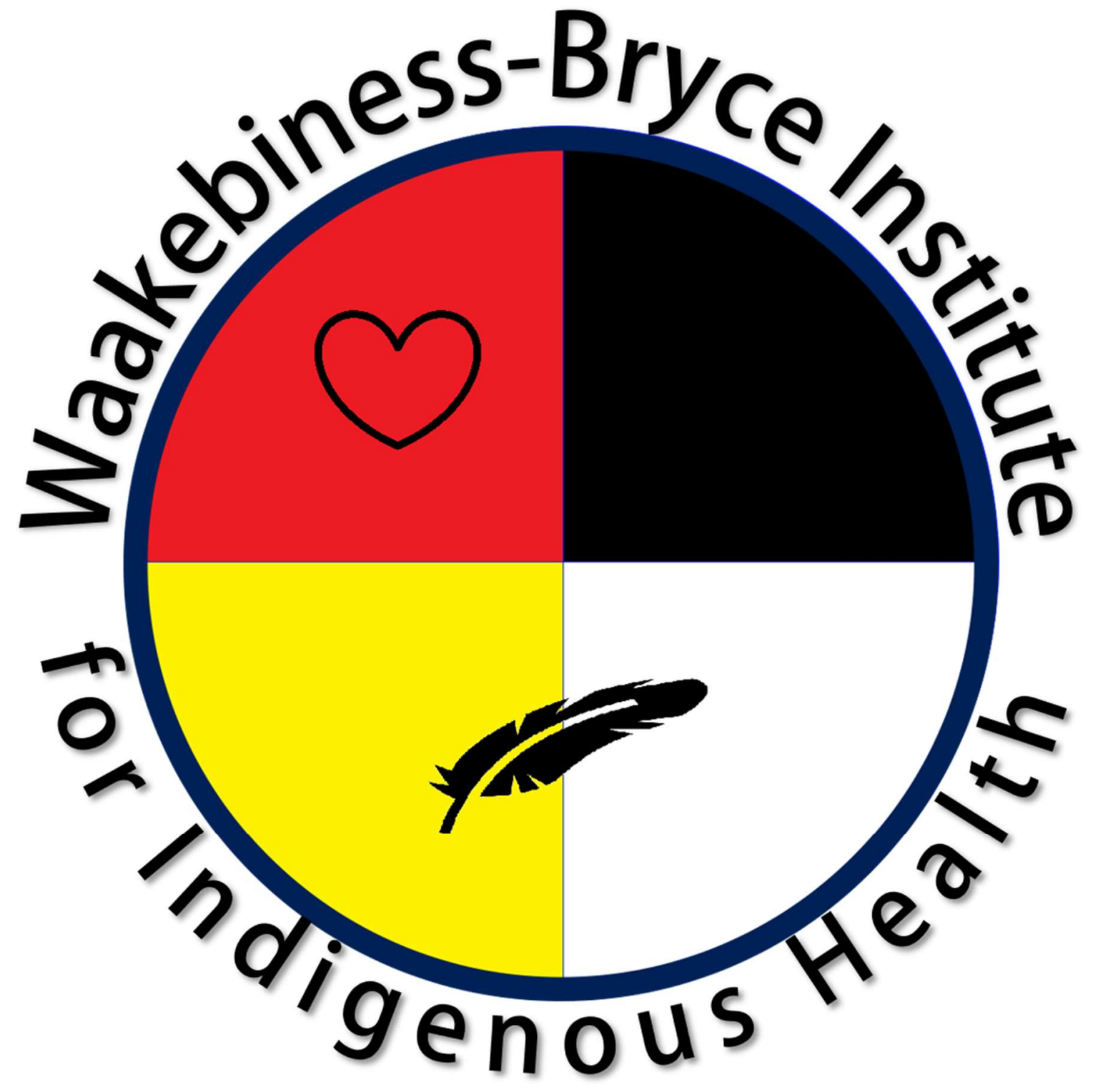




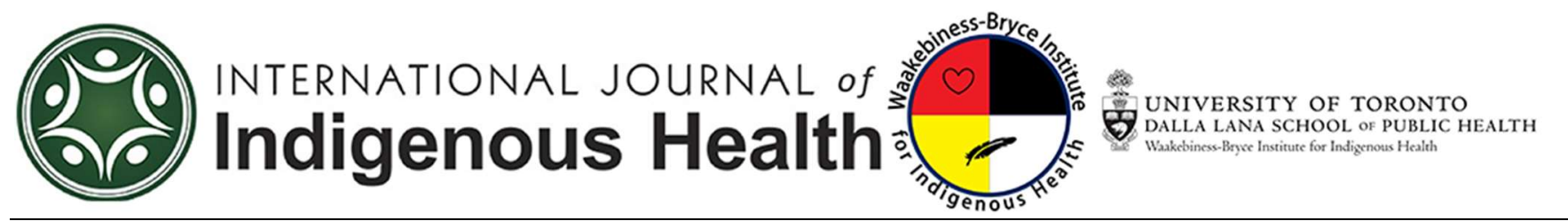

Volume 13

Issue 2. Death and Dying

Article 3

DOI 10.18357/ijih.v13i2.32062

December 2018

\section{The End of Life is an Auspicious \\ Opportunity for Healing: Decolonizing Death and Dying for Urban Indigenous People}

Michael Anderson, MD, MSc, FRCSC

The Temmy Latner Centre for Palliative Care, Sinai Health System. University of Toronto.

mike.anderson@utoronto.ca

Gemma Woticky, BA (Hons.), MPH

Dalla Lana School of Public Health, University of Toronto.

gemma.woticky@mail.utoronto.ca

Follow the International Journal of Indigenous Health at:

https://jps.library.utoronto.ca/index.php/ijih/index

Recommended Citation

Anderson, M., Woticky, G. (2018). The End of Life is an Auspicious Opportunity for Healing: Decolonizing

Death and Dying for Urban Indigenous People. IJIH,13(2),48-60. DOI 10.18357/ijih.v13i2.32062 


\title{
The End of Life is an Auspicious Opportunity for Healing: Decolonizing Death and Dying for Urban Indigenous People
}

\begin{abstract}
The majority of Indigenous peoples on Turtle Island (North America) now live in urban settlements, and likely may die in urban spaces. Based upon academic and grey literature searches in 2018 of Indigenous death, dying, grieving, and palliative care in Canada, there is a near absence of information exploring this pivotal life event in the urban context. The diversity of urban Indigenous identities, lived experiences, and degree of connection to Indigenous culture highlights the complexity of the interconnection of death, Indigeneity, and urbanity. Fortunately, signs exist of Indigenous cultural and ceremonial revitalization in urban spaces, and the end of life offers an auspicious opportunity for healing from the intergenerational trauma arising from colonization.

Despite the plurality of cultures in urban settlements on Turtle Island, colonization informs and dominates most systems, including the framing of death and dying as a medical event. However, in my experience, death is more about culture and community. Reconciliation for urban Indigenous communities involves negotiating this challenging paradox between colonial and Indigenous worldviews. Rather than developing new strategies, I posit that existing knowledge - the Medicine Wheel and the Two Row Wampum - offer a vision for restoring respect, balance, and spirit to the endof-life journey. The Medicine Wheel and the Two Row Wampum teachings offer an Indigenous theoretical framework to consider the complex space created by the interconnection of death, Indigeneity, and urbanity and offers a strength-based approach to guide future end-of-life research, policy, and practice to improve the end-of-life experience for urban Indigenous communities.
\end{abstract}

\section{Keywords}

Indigenous end-of-life care, palliative care.

\section{Creative Commons Licence (ब) $\otimes \otimes \Theta$}

This work is licensed under a Creative Commons Attribution-Noncommercial-No Derivative Works 4.0 License. 


\section{Introduction}

\section{Introduction}

"I'm just a human being trying to make it in a world that is very rapidly losing its understanding of being human" John Trudell - Indigenous rights activist, poet, musician

The majority of Indigenous people on Turtle Island (North America) now live in urban settlement (Statistics Canada, 2013). It follows that they may likely die in urban spaces. Based upon academic and grey literature searches in 2018 of Indigenous death, dying, grieving, and palliative care in urban centers in Canada, there is a near absence of information exploring this pivotal life event in an urban context. There is also limited information in general related to death, dying, and grieving for Indigenous communities to inform policy, practice, and education (Kelley, 2010). This is not to suggest that Indigenous communities lack knowledge about this important life transition, but the oral nature of Indigenous knowledge is vulnerable to the disruptive effects of cultural genocide. There is a significant risk of loss of Indigenous knowledge as current Elders themselves pass into the spirit world.

To properly begin this discussion, I locate myself as an individual who strives to walk in two worlds, as many urban Indigenous people do. I was born and raised in the Greater Toronto Area and am part of Toronto's urban Indigenous community. I am of Mohawk (Bear Clan) and English descent with family roots in Tyendinaga Mohawk Territory. Reclaiming aspects of Indigenous identity and culture that were suppressed by colonial legislation is of great importance to me. As a surgeon I have routinely witnessed medicalized death. The modern health care system frames death as a medical event and primarily considers the physical aspects of death. This approach was unsatisfying and discordant with my personal values as an Indigenous person. I vividly recall delivering the news of a terminal cancer diagnosis to a young First Nations man. After a discussion of available medical treatment options, he said it was time for him to return to his community to heal - "to get well." He was accepting of his physical circumstances but recognized the opportunity for healing. Improving access and availability of both traditional Indigenous healing and western medical palliative care is important to afford urban Indigenous people opportunities for healing at the end of life.

I am part of Toronto's urban Indigenous community. As such, when I walk the last stages of my life, I want the option of a different path than the health care system currently supports - one informed by Indigenous knowledge and infused with Indigenous culture. Death is not meant to be a medical event. In my experience, it is about culture and community. The Indigenous relationship with death recognizes it as integral to our understanding of life. By applying the teachings of the Medicine Wheel and the Two Row Wampum, I will offer a theoretical framework to consider the complex space created by the interconnection of death, Indigeneity, and urbanity. This space can be mediated by a dialogue about changing the shape of this relationship from hierarchal to circular - colonial to Indigenous. 


\section{Indigeneity in Urban Settlements}

The dramatic increase in the Indigenous population in Canada over the last decade largely results from ethnic mobility (the phenomenon by which individuals and families change their ethnic affiliation) and much of this growth has occurred in urban settlements (Peters \& Andersen, 2013). The urban Indigenous community is highly diverse in their identity, lived experiences, and degree of connection to Indigenous culture (Peters \& Andersen, 2013). Many urban Indigenous people are second and third generation city dwellers, thus their Indigeneity may not be primarily defined by connection to ancestral land (Peters \& Andersen, 2013). Contemporary urban Indigenous people "choose from a variety of other resources to construct identities, including pan-Aboriginal cultures and activities in urban areas"(Peters \& Andersen, 2013). Urban Indigenous communities are often arranged around cultural and health care organizations.

Cultural engagement has been shown to be beneficial to the health and well-being of Indigenous people (Auger, Howell, \& Gomes, 2016; Gone, 2011; Gone \& Looking, 2011). However, government policies aimed at cultural extermination and assimilation have resulted in a tremendous loss of Indigenous knowledge, including end-of-life practices and ceremonies. Cultural disruption poses a real risk of permanently losing much of this knowledge given the oral nature of Indigenous knowledge. Rediscovering traditional death ceremonies, increasing access to cultural supports, enhancing death education, and improving relationships with health service providers are of great importance to urban Indigenous people (Anderson, Chalklin, Downey, Lee, \& Rodin, 2017). Fortunately, there are signs of Indigenous cultural and ceremonial revitalization in urban spaces and the end of life stage offers an auspicious healing opportunity.

\section{Indigenous Concepts of Death and Dying}

The absence of a word for death in most Indigenous languages underscores how differently the end-of-life experience is constructed by Indigenous people. Despite being a very heterogeneous group, Indigenous people worldwide share elements of a common spirituality and worldview (Duggleby et al., 2015). The colonial worldview frames death through a linear, biomedical, and physical lens. Indigenous people view themselves as a spirit having a human experience (P. Keshane, personal communication, Jan 2017). Birth and death are inextricably linked as a transition of the spirit through this world. Thus, the end-of-life is a transition of the spirit rather than solely the end of the body. The last stages of life are an auspicious opportunity for healing of the spirit - and spirit is healed through ceremony (J. Longboat, personal communication, March 2016).

The following is an excerpt from Basil Johnston's (Johnston, 2010) book in which he recounts the Anishinaabe story of the Gift of the Stars (Annangoog Meegiwaewinan), the origins of children to the physical world. It is transcribed here in its entirety to honor the knowledge embedded in the story and to allow for a wholistic interpretation of its message. 
Johnston begins this story about a five year old, Southwind, and the teachings from his grandmother:

"What are stars, grandmother?" he asked. "Babies," his grandmother answered. Southwind looked back up. The stars looked like sparks. But babies they must be. Had his grandmother not said so? So many babies. They filled the entire sky. A star fell. Southwind gasped. "Oh! Grandma! The baby is going to get hurt!" "Don't fret grandson. The baby won't get hurt. It will fall gently as a feather into someone's arms. Someone's going to receive a wonderful gift tonight. It will make them happy." Southwind's grandmother explained. "What kind of gift?". Some woman is going to get a baby that will make her happy," Southwind's grandmother said. Southwind looked back up into the sky. Not a word did he say. His mind was too small, too young to understand how stars and babies and gifts could be the same thing. To help Southwind understand, his grandmother told him, "One time you were a little star and you came down as a baby to your mother and to your father and to all of us. You made us all very happy. If ever a star falls near you, take it. Take it home! Look after it. It is a great gift that will make you happy." (Johnston, 2010, p. 19.)

Southwind's grandmother explained that boys don't receive babies, but they do receive different gifts.

"In that moment Southwind wanted a star to fall nearby so that he could take it up, bring it home and look after it. But none ever fell nearby. Always they fell far away. Always they were gifts for somebody else but not for him. For five years Southwind watched stars with his grandmother. Then he stopped going with his grandmother. Looking at stars was boring. Three more years went by. His grandmother fell ill. One night Southwind went out to the knoll where his grandmother used to watch the stars. Before Southwind got to the crest of the little hill, a star fell and it fell just the other side of the hill, where there was a pond. Southwind ran up the knoll and then down the other side to the edge of the pond. But there was nothing in the pond, nothing but white flowers that he'd never before seen. There was no gift. He turned to go back home. "Take me. Take me home. I am medicine. I will make your grandmother well!" a voice said. The little voice came from the middle of the pond. But there was no one there. Again and again the voice called, "Take me! Take me home with you." At last Southwind entered the water, waded out to the middle of the pond. In front of him was the white flower that called out. "Take me! Take me home! I am medicine. I am your gift." Southwind was about to yank the flower from its stalk when it screamed, "No! All of me! All of me!" But it was not an easy thing to lift the flower from its bed. To do this Southwind had to go underwater many times to dig the long root of the flower from its muddy bed. When he finally dug the flower out, Southwind took it home. With the flower Southwind's father made a medicine. They gave it to the old sick woman. The medicine made her better. Some months later Southwind and his grandmother were standing on the knoll studying the stars. He said to her, "No'okomiss, the flower gift that I received; it was really meant for you, wasn't it?. In a way it is. But it was meant for everybody. But that's the way all human gifts are." (Johnston, 2010.p, 20). 
The reader can interpret the various lessons within this story, but it is noteworthy that this is a children's story, which educates about the cycle of life. This story addresses the entering of the spirit into this physical world, by the birth of a baby. In death, the spirit is returning to the stars: departing the body as the physical body returns to the first mother, mother earth.

In 2016, a diverse group of highly engaged key informants from community, clinical, policy, government, and educational perspectives gathered to consider First Nations, Inuit, and Metis (FNIM) palliative and end-of-life care issues (Anderson et al., 2017). Numerous themes emerged from facilitated discussions and world cafes including: differing urban and remote community experiences, the need for death education, cultural barriers, challenging interactions with western medical personal, systemic racism, opportunities for healing, and the absence of spirit in the biomedical palliative care system (Anderson et al., 2017). The importance of this topic in the urban context has been affirmed by multiple sources including Indigenous Elders, the Toronto Indigenous Health Advisory Circle, and Anishnawbe Health Toronto.

\section{The Medicine Wheel}

The Medicine Wheel is a circular, wholistic, relational representation of the elements of life including the physical, emotional, mental, and spiritual aspects of self in addition to life stages, seasons, sacred medicines, and the four directions (Dapice, 2006). The Medicine Wheel is widely used for health and wellbeing including as a tool for healing from the imbalance caused by colonialism (Dapice, 2006). Its use is congruent with a theoretical framework for conceptualizing death and dying as it represents the cycle of life. Furthermore, it opens the space to challenge the idea that the only death is physical and the possibility that death of all parts of self may not occur simultaneously. The explicit nature of spirit in the medicine wheel is critical at the end of life since the modern healthcare model rarely makes space for spirit. Using examples to explore this concept, I will artificially divide the discussion into the four realms of self and subsequently demonstrate the impossibility of separating them - again consistent with the Indigenous worldview of interconnectedness and relational accountability.

\section{Kaswentha - The Two Row Wampum}

Based upon the Haudenosaunee principles of peace, respect, and friendship, the Two Row Wampum documents the relationship between Turtle Island's Onkwehonweh (original people) and the first European explorers. Indigenous legal scholar Robert A. Williams Jr (1990). describes the Two Row Wampum:

When the Haudenosaunee first came into contact with the European nations, treaties of peace and friendship were made. Each was symbolized by the Gus-Wen-Tah, or Two Row Wampum. There is a bed of white wampum which symbolizes the purity of the agreement. There are two rows of purple, and those two rows have the spirit of your ancestors and mine. There are three beads of wampum separating the two rows and they symbolize peace, friendship and respect. 
These two rows will symbolize two paths or two vessels, travelling down the same river together. One, a birch bark canoe, will be for the Indian people, their laws, their customs and their ways. The other, a ship, will be for the white people and theirs laws, their customs, and their ways. We shall each travel the river together, side by side, but in our own boat. Neither of us will try to steer the other's vessel. (p. 327)

Thus, this belt of wampum reflects both the separation and interaction of First Nations people and the newcomers that continues to this day. This relationship applies to modern urban settlements with the same veracity as the original agreement in 1613. I propose that the modern urban Indigenous experience is rooted in the three white rows between the two purple rows - the space in between. This space in between the two rows seems congruous with post-colonial scholar Homi Bhabha's concept of a 'third space' (Bhabha, 2004) and Willie Ermine's ethical space (Ermine, 2004). This is a liminal space where two or more cultures interact. Ermine (2004) describes the ethical space as:

"The in-between space, relative to cultures, [is] created by the recognition of the separate realities of histories, knowledge traditions, values, interests, and social, economic and political imperatives. The positioning of these two entities, divided by the void and flux of their cultural distance, and in a manner that they are poised to encounter each other, produces a significant and interesting notion that has relevance in research thought. The positioning of the two entities creates the urgent necessity for a neutral zone of dialogue." (p. 20)

In Haudenosaunee teachings this area is defined by peace, friendship, and respect. The urban Indigenous lived experience is often one of variable cultural connection; neither completely in the canoe or in the ship but in some third space between.

\section{Conceptualizing Urban Indigenous Death and Dying: The Medicine Wheel and Two Row Wampum Exist in Urban Settlements}

The Medicine Wheel and the Two Row Wampum offer a vision for restoring respect, balance, and spirit to the end-of-life journey. These two teachings can be used to navigate the unique challenges at the intersection of death, urbanity, and Indigeneity. Together they act as an Indigenous theoretical framework for end-of-life research, policy, and practice. Despite the plurality of cultures in urban settlements on Turtle Island, colonization informs and dominates most systems. Western, colonial worldviews are transactional, hierarchal, and extractive by design. This is the antithesis of relational, collectivist, and egalitarian Indigenous worldviews. Reconciliation for urban Indigenous communities involves negotiating this challenging paradox. However, rather than developing new strategies, I posit existing knowledge - the Medicine Wheel and the Two Row Wampum - can offer an attractive way forward.

The Medicine Wheel does not frame aspects in isolation, opposition, or as separable. Intrinsic to the Medicine Wheel is a pathway for change, healing, and reconciliation. Urban Indigenous people do not have the option of living in isolation - although aspects of the colonial system continue to strive to achieve this. As a healing tool, the Medicine Wheel can help address imbalances caused by colonialism, 
including in relationships by (re)connecting with Indigenous culture. This is of great importance to Indigenous people at the end of life.

The original tenets of the Two Row Wampum treaty offer a vision for weaving a relationship that is not dominated by the hegemonic culture. Approaches to this relationship that involve fitting the circular (Indigenous) into a hierarchy (western) have routinely failed Indigenous people. Trying to extract the "best" of both worlds inevitably results in the dominant culture deciding what qualifies as the "best". While the Two Row Wampum explicitly prohibits steering each other's vessels, it recognizes we travel the river together and provides a space for interaction. This space between the Indigenous canoe and the western ship is mediated by peace, friendship, and respect. For urban Indigenous people, existing in this liminal, ethical (third) space involves the praxis of building meaningful relationships with both the Indigenous and the non-Indigenous. Paolo Freire's concept of praxis refers to the linking of theory, informed action, and critical reflection (Freire, 2000). Dialogue, the flow of meaning, is the principle mediator of praxis. I propose that dialogue, grounded in peace, friendship, and respect, and informed by the Medicine Wheel and Two Row Wampum teachings, can improve the end-of-life experience for urban Indigenous communities.

\section{Physical}

The last stages of life frequently involve challenges to one's physical wellbeing. The western health care system focuses on the physical realm. Nowhere is this more apparent than in the approach to pain. Despite recognizing the concept of 'total pain,' (Mehta, 2008; Wein, 2010) in reality, pain is viewed almost exclusively in terms of physical pain as evidenced by the near ubiquitous use of opiates as a remedy (Middleton-Green, 2008; Montes-Sandoval, 1999). An Indigenous approach would recognize the interconnectedness of the physical, emotional, spiritual, and mental aspects of pain in endeavoring to mitigate the total experience of pain (Gone, 2009). What does this look like? Through ceremonies such as drumming and smudging which can be incorporated into institutional policies, pain management can take a more Indigenous perspective if combined with traditional Indigenous healing and/or healing circles. Reducing any aspect of pain reduces total pain.

The physical structure and regulations of health care institutions are routinely hostile to Indigenous people. This is relevant in urban settlements because most of us will die in hospitals, despite our stated preferences to die at home (Kelly et al., 2009; McGrath, 2007; St Pierre-Hansen, Kelly, Linkewich, Cromarty, \& Walker, 2010). Dying at home can be challenging given the high degree of mobility, precarious housing, and homelessness affecting urban Indigenous communities (King, Smith, \& Gracey, 2009; Snyder \& Wilson, 2015). Physical and policy limits on the number of people allowed in a room and failing to provide adequate space for family in many institutions precludes the role of the larger family, kin, and community networks that coalesce to support a dying individual. These barriers hinder the ability of a broad network of family and kin to empower the spirit for transition (Duggleby et al., 2015). Institutional policies in long term care homes, hospices, and health care facilities often prevent important ceremonies such as smudging or the pipe ceremony. 
The physical layout of hospitals is intended to hide death. People enter through brightly lit, well appointed, visible front doors but the deceased are removed through unseen service doors often located at the rear of the building. The deceased are rapidly cocooned in body bags, rendered invisible, and moved to places others cannot go or see. It is as if death is shameful and to be hidden. This isn't surprising, given the illness-based, medical model's perception of death as a failure. This presents a barrier for Indigenous people who may wish to maintain a connection to their recently deceased loved one. Touching and bathing the body is an act of love and respect which can empower and release the spirit and support grieving. Superimposed upon the hidden nature of death in institutions is the invisibility many Indigenous people already experience in the health care system. For Indigenous people, death in urban hospitals is another form of systemic racism that further marginalizes Indigenous ways of knowing.

\section{Mental}

There are many aspects of the mental realm which reflect the tensions between Indigenous and non-Indigenous ways of thinking. Families speak of the difficulty reconciling the health care system's drive for expediency with Indigenous consensual approaches to decision-making. An example of this is seen in the determination of substitute decision makers (SDM). The colonial approach to defining a SDM is hierarchal and legally framed by way of a presumed series of relations based on blood and lineage. Even the term lineage is inconsistent with an Indigenous way of viewing the world. Indigenous decision-making is not rooted in hierarchical authority but instead in consensus building.

I was recently told the story of an Indigenous man who was gravely injured in an accident. The healthcare team felt he was unlikely to recover and decisions regarding care were necessary. The medical team wanted an expedient decision from a SDM dictated by a non-Indigenous, hierarchal, legal protocol. The family, kin, and community gathered to take an Indigenous approach to decision-making. They sat in a circle and shared stories about this man's life, with people stepping out of the circle after each round if they felt others knew him better. This continued until only three individuals remained. None fit the legal criteria for SDM but everyone agreed they had the deepest understanding of who he was as a human being and what his care decisions would have been. Thus, a community-based, consensual approach to decision-making was employed resulting in a less expedient but more appropriate decision. This is an example of how difficult conversations may require more time, but grounding decision-making in authentic relationships and Indigenous approaches to dialogue is essential to achieve outcomes acceptable to Indigenous communities. A final sad comment is necessary here though. Although the health care professionals were accepting of this decision-making strategy, and health care colleagues I have discussed this with find the approach appealing, the actual SDM transaction had to be carried out in a colonial, hierarchal manner.

\section{Emotional}

The sting of death can be lessened by family and community support or heightened if the circumstances of death are re-traumatizing. Intergenerational trauma expands unless addressed and this 
is particularly true for those grieving the loss of a loved one. Colonization (e.g., the Indian Act, residential school system, Sixties Scoop, forced relocation, child welfare system) is at the root of intergenerational trauma, and has resulted in many Indigenous people experiencing repeated and ongoing traumas from a wide variety of sources, including health care professionals and institutions (Barker, Goodman, \& DeBeck, 2017; Howard, 2014; Kirmayer, Gone, \& Moses, 2014; Myhra, 2011; Reeves \& Stewart, 2017). Therefore, death and dying may retraumatize individuals and communities resulting in expanded intergenerational trauma unless affected people are afforded opportunities to address both past and ongoing traumas (Gone, 2013). The Medicine Wheel became unbalanced through colonial practices. Restoring balance to the Medicine Wheel through decolonization offers a path to heal. Dying well, within institutions, requires more than cultural safety - it requires empathy and dignity (Chochinov, 2013; Thompson \& Chochinov, 2008). A health care system that is unable to deliver on these most basic human needs has failed. Sadly, Indigenous people encounter this failure routinely.

In urban settings it is common to encounter stories of Indigenous people experiencing challenges accessing elders, traditional healers, or cultural supports as they are dying due to communication barriers with western healthcare institutions (Harrison J. personal communication, Jan 2017). Even when access to cultural support does occur, it frequently occurs late in their journey (Vautour, J. personal communication, Mar 2017). This limits the healing opportunities for individuals and families, particularly for people wishing to explore their identity and culture at the end of life. The benefits ascribed to early palliative care are not routinely afforded to Indigenous people. Improved relationships between the health care system and Indigenous organizations may enhance the opportunities for emotional support through connection to community and culture.

\section{Spiritual}

Lastly, and most importantly, is the spiritual realm. In western health care there is an aversion to all things spiritual. Health care professionals and institutions continue to erect physical as well as policy barriers which impede communal and spiritual activities at the end of life. As Indigenous people, 'we are a spirit having a human experience.' It's not surprising that one of the most sought out services at the end of life is receiving one's spirit name. Creating space for spirit is both paramount and challenging at the end of life.

The last stages of life are an auspicious opportunity for healing of the spirit. Spirit is healed through ceremony. It is only very recently that Indigenous ceremonies are being permitted in some health care settings. That ceremonies (e.g., smudging, pipe ceremony) are still restricted in many institutional settings is particularly egregious given the history of legislated bans on Indigenous ceremony and culture. The Indian Act of 1876 outlawed Indigenous cultural and ceremonial practices in an effort to force assimilation (Joseph, 2018), the effects of which continue to be felt by many Indigenous people who are seeking to reclaim their cultural and spiritual practices. Although institutional policies regularly restrict Indigenous ceremonies, in my experience most health care workers are genuinely curious and accepting of Indigenous ceremonies. It is evident that there remains a 
disconnect between policy and practice that needs to be bridged. This too speaks to the need to construct meaningful relationships.

\section{Discussion}

The end of life offers an auspicious opportunity for healing. This isn't limited to the dying individual but extends to all of our relations. For urban Indigenous communities the network of relationships can be complex to navigate as identity and culture are not always apparent or accessible. The Medicine Wheel and the Two Row Wampum do exist in urban settlements - they may just be more difficult to find.

So how do we move forward? The current analysis and theoretical framework offer a strengthbased approach for building future research and informing policy and practice. The interconnection of death, Indigeneity, and urbanity creates a new space to contemplate. Exploring this space involves building meaningful relationships and the praxis of changing the relationship's shape from hierarchal to circular - colonial to Indigenous. This praxis can be mediated by dialogue, particularly Indigenous nonhierarchal, circular, approaches to dialogue. Applying the teachings of the Medicine Wheel and the Two Row Wampum offers a framework to improve the end-of-life experience for urban Indigenous communities.

\section{References}

Anderson, M. A., Chalklin, L., Downey, B., Lee, L., \& Rodin, G. (2017). A Search for Solutions: A Gathering on Palliative and End-of-Life Care for First Nations, Inuit, and Metis Peoples. Retrieved from http://gippec.org/couch/uploads/file/gippec-symposium-report-2016.pdf

Auger, M., Howell, T., \& Gomes, T. (2016). Moving toward holistic wellness, empowerment and selfdetermination for Indigenous peoples in Canada: Can traditional Indigenous health care practices increase ownership over health and health care decisions? Can J Public Health, 107(4-5), e393e398. doi:10.17269/cjph.107.5366

Barker, B., Goodman, A., \& DeBeck, K. (2017). Reclaiming Indigenous identities: Culture as strength against suicide among Indigenous youth in Canada. Can J Public Health, 108(2), e208-e210. doi:10.17269/cjph.108.5754

Bhabha, H. K. (2004). The location of culture. London ; New York: Routledge.

Chochinov, H. M. (2013). Dignity in care: time to take action. J Pain Symptom Manage, 46(5), 756-759. doi:10.1016/j.jpainsymman.2013.08.004 
Dapice, A. N. (2006). The medicine wheel. J Transcult Nurs, 17(3), 251-260. doi: $10.1177 / 1043659606288383$

Duggleby, W., Kuchera, S., MacLeod, R., Holyoke, P., Scott, T., Holtslander, L., . . Chambers, T. (2015). Indigenous people's experiences at the end of life. Palliat Support Care, 13(6), 17211733. doi:10.1017/S147895151500070X

Ermine, W. (2004). The Ethics of Research Involving Indigenous Peoples. Retrieved from Indigenous Peoples' Health Research Centre:

Freire, P. (2000). Pedagogy of the oppressed (30th anniversary ed.). New York: Continuum.

Gone, J. P. (2009). A community-based treatment for Native American historical trauma: prospects for evidence-based practice. J Consult Clin Psychol, 77(4), 751-762. doi:10.1037/a0015390

Gone, J. P. (2011). The red road to wellness: cultural reclamation in a Native First Nations community treatment center. Am J Community Psychol, 47(1-2), 187-202. doi:10.1007/s10464-010-9373-2

Gone, J. P. (2013). Redressing First Nations historical trauma: theorizing mechanisms for indigenous culture as mental health treatment. Transcult Psychiatry, 50(5), 683-706. doi:10.1177/1363461513487669

Gone, J. P., \& Looking, P. E. (2011). American Indian culture as substance abuse treatment: pursuing evidence for a local intervention. J Psychoactive Drugs, 43(4), 291-296. doi:10.1080/02791072.2011.628915

Howard, H. A. (2014). Canadian residential schools and urban indigenous knowledge production about diabetes. Med Anthropol, 33(6), 529-545. doi:10.1080/01459740.2013.828722

Johnston, B. (2010). Gift of the stars = Anungook gauh meenikooying. Wiarton, Ont.: Kegedonce Press.

Joseph, B. (2018). 21 Things You May Not Know About the Indian Act: Helping Canadians Make Reconciliation with Indigenous Peoples a Reality. Vancouver, BC: Indigenous Relations Press.

Kelley, M. L. (2010). An indigenous issue: why now? J Palliat Care, 26(1), 5.

Kelly, L., Linkewich, B., Cromarty, H., St Pierre-Hansen, N., Antone, I., \& Giles, C. (2009). Palliative care of First Nations people: a qualitative study of bereaved family members. Can Fam Physician, 55(4), 394-395 e397.

King, M., Smith, A., \& Gracey, M. (2009). Indigenous health part 2: the underlying causes of the health gap. Lancet, 374(9683), 76-85. doi:10.1016/S0140-6736(09)60827-8

Kirmayer, L. J., Gone, J. P., \& Moses, J. (2014). Rethinking historical trauma. Transcult Psychiatry, 51(3), 299-319. doi:10.1177/1363461514536358

McGrath, P. (2007). 'I don't want to be in that big city; this is my country here': research findings on Aboriginal peoples' preference to die at home. Aust J Rural Health, 15(4), 264-268.

doi:10.1111/j.1440-1584.2007.00904.x 
Mehta, A., Chan, L. (2008). Understanding the concept of "total pain": A prerequisite for pain control. Journal of Hospice and Palliative Nursing, 10(1), 26-34. DOI:

10.1097/01.NJH.0000306714.50539.1a

Middleton-Green, L. (2008). Managing total pain at the end of life: a case study analysis. Nurs Stand, 23(6), 41-46. doi:10.7748/ns2008.10.23.6.41.c6708

Montes-Sandoval, L. (1999). An analysis of the concept of pain. J Adv Nurs, 29(4), 935-941. https://doi.org/10.1046/j.1365-2648.1999.00971.x

Myhra, L. L. (2011). "It runs in the family": intergenerational transmission of historical trauma among urban American Indians and Alaska Natives in culturally specific sobriety maintenance programs. Am Indian Alsk Native Ment Health Res, 18(2), 17-40.

Statistics Canada. (2013). 2011 National Household Survey: Aboriginal Peoples iin Canada. First Nations People, Métis and Inuit. The Daily, May 8, 2013.

Peters, E. J., \& Andersen, C. (2013). Indigenous in the city : contemporary identities and cultural innovation. Vancouver: UBC Press.

Reeves, A., \& Stewart, S. (2017). Healing the Spirit: Exploring Sexualized Trauma and Recovery among Indigenous Men in Toronto. Am Indian Alsk Native Ment Health Res, 24(1), 30-60. doi:10.5820/aian.2401.2017.30

Snyder, M., \& Wilson, K. (2015). "Too much moving...there's always a reason": Understanding urban Aboriginal peoples' experiences of mobility and its impact on holistic health. Health Place, 34, 181-189. doi:10.1016/j.healthplace.2015.05.009

St Pierre-Hansen, N., Kelly, L., Linkewich, B., Cromarty, H., \& Walker, R. (2010). Translating research into practice: developing cross-cultural First Nations palliative care. J Palliat Care, 26(1), 41-46.

Thompson, G. N., \& Chochinov, H. M. (2008). Dignity-based approaches in the care of terminally ill patients. Curr Opin Support Palliat Care, 2(1), 49-53. DOI: 10.1097/SPC.0b013e3282f4cb15doi:10.1097/SPC.0b013e3282f4cb15

Wein, S. (2010). A view of life in death. J Palliat Care, 26(3), 205-206.

Williams, R. A. (1990). The American Indian in western legal thought: the discourses of conquest. New York: Oxford University Press. 